\title{
Natural and Forced North Atlantic Hurricane Potential Intensity Change in CMIP5 Models*
}

\author{
Mingfang Ting, Suzana J. Camargo, Cuihua Li, and Yochanan Kushnir \\ Lamont-Doherty Earth Observatory, Columbia University, Palisades, New York
}

(Manuscript received 15 July 2014, in final form 15 February 2015)

\begin{abstract}
Possible future changes of North Atlantic hurricane intensity and the attribution of past hurricane intensity changes in the historical period are investigated using phase 5 of the Climate Model Intercomparison Project (CMIP5), multimodel, multiensemble simulations. For this purpose, the potential intensity (PI), the theoretical upper limit of the tropical cyclone intensity given the large-scale environment, is used.

The CMIP5 models indicate that the PI change as a function of sea surface temperature (SST) variations associated with the Atlantic multidecadal variability (AMV) is more effective than that associated with climate change. Thus, relatively small changes in SST due to natural multidecadal variability can lead to large changes in PI, and the model-simulated multidecadal PI change during the historical period has been largely dominated by AMV. That said, the multimodel mean PI for the Atlantic main development region shows a significant increase toward the end of the twenty-first century under both the RCP4.5 and RCP8.5 emission scenarios. This is because of enhanced surface warming, which would place the North Atlantic PI largely above the historical mean by the mid-twenty-first century, based on CMIP5 model projection.

The authors further attribute the historical PI changes to aerosols and greenhouse gas (GHG) forcing using CMIP5 historical single-forcing simulations. The model simulations indicate that aerosol forcing has been more effective in causing PI changes than the corresponding GHG forcing; the decrease in PI due to aerosols and increase due to GHG largely cancel each other. Thus, PI increases in the recent 30 years appears to be dominated by multidecadal natural variability associated with the positive phase of the AMV.
\end{abstract}

\section{Introduction}

The projected change in future hurricane intensity as a result of anthropogenic forcing is a topic of great societal concern due to the disastrous consequences associated with tropical storms. As recent examples, the infamous Hurricane Katrina in 2005 and Hurricane Sandy in 2012 brought huge amounts of damage to the Gulf Coast and the U.S. Northeast, respectively (Graumann et al. 2005; Blake et al. 2013). The total estimated damage due to Hurricane Katrina exceeded USD 100 billion, and the death toll exceeded 1300. The storm also resulted in a displacement of 250000

* Lamont-Doherty Earth Observatory Contribution Number 7880.

Corresponding author address: Mingfang Ting, Lamont-Doherty Earth Observatory, Columbia University, 61 Route 9W, Palisades, NY 10964.

E-mail: ting@ldeo.columbia.edu people, a higher number than the Dust Bowl years of the 1930s (Graumann et al. 2005). Hurricane Sandy also caused widespread impacts, including 72 storm-associated deaths, a total of 650000 houses that were either damaged or destroyed, 8.5 million customers left without power for an extended period of time, and a total of over USD 50 billion in damages (Blake et al. 2013).

Recent studies using a globally consistent reanalysis of hurricane intensity (Kossin et al. 2007, 2013; Elsner et al. 2008) have shown a robust upward trend of Atlantic hurricane intensity in the last decades. Emanuel (2005) showed that the North Atlantic tropical cyclone power dissipation, defined as the integral over the life span of past storms' maximum surface wind speed cubed, has increased substantially since the 1970s and followed closely the rise in tropical North Atlantic sea surface temperatures (SSTs) during the same period.

Ting et al. (2009) used the signal-to-noise maximizing empirical orthogonal function (S/N EOF) analysis to separate the radiatively forced component of surface temperature from the internal multidecadal variations and 
found that the Atlantic main development region (MDR) SSTs have increased significantly as a result of both global warming and the upward phase of the Atlantic multidecadal variability (AMV) since the 1970s. DelSole et al. (2011) also showed that the nonuniform warming of the observed global mean SST, such as the accelerated warming during 1977-2008, was largely due to internal multidecadal variability. Thus, it is extremely important to understand the relative contribution of external radiative forcing versus internal multidecadal variability to the recent hurricane intensity increase in order to better project future hurricane intensity changes.

It is generally expected that the probability distribution of tropical cyclone intensity will shift toward stronger storms in the future (e.g., Emanuel 1987, 2013; Bengtsson et al. 1996, 2007; Henderson-Sellers et al. 1998; Knutson et al. 1998; Knutson and Tuleya 2004; Knutson et al. 2010, 2013; Murakami et al. 2012), potentially leading to increased damage by these storms (Emanuel 2011; Lin et al. 2012; Mendelsohn et al. 2012). Previous studies have shown this shift theoretically (e.g., Emanuel 1987; Holland 1997), using high-resolution modeling studies (e.g., Knutson and Tuleya 2004; Bender et al. 2010; Hill and Lackmann 2011; Knutson et al. 2010, 2013; Murakami et al. 2012; Maloney et al. 2014), as well as using statistical analysis (Zhao and Held 2010; Villarini and Vecchi 2013) and other downscaling techniques (Emanuel et al. 2008; Emanuel 2013). However, projections of the hurricane potential intensity (PI; Emanuel 1988) based on phase 3 of the Climate Model Intercomparison Project (CMIP3) models' twenty-first-century simulations, particularly in the Atlantic basin, have not shown a consistent upward trend (Vecchi and Soden 2007; Vecchi et al. 2008). The latter papers argue that changes in both local and remote SST contribute to the PI changes, and it is the relative warming of the local SST with respect to the tropic-wide warming that determines the hurricane intensity, as discussed in Swanson $(2007,2008)$. For the tropical North Atlantic, since local warming is weaker than the tropicwide warming due to anthropogenic forcing, the PI shows no obvious trend in the twenty-first century (Fig. 2 in Vecchi and Soden 2007). More recently, Emanuel and Sobel (2013) showed that, while relative SST is a good proxy for potential intensity when forcing is strictly local, it cannot capture potentially important changes in potential intensity that arise from global-scale changes in forcing. Furthermore, Emanuel and Sobel (2013) showed that the hurricane PI varies much more rapidly with SST in response to changing surface wind speed than in response to solar and $\mathrm{CO}_{2}$ radiative forcing.

Consistent with previous results indicating a tempered influence of global tropical warming on the Atlantic hurricane potential intensity and local environmental conditions, Camargo et al. (2013) used a suite of model simulations with prescribed observed SSTs and showed that nonlocal SST tends to reduce the PI associated with locally forced warming by changing upper-level atmospheric temperatures. These results suggest that the observed late-twentieth-century increase in hurricane power dissipation index (Emanuel 2005), while closely related to the tropical Atlantic SST increase, may not have been dominated by anthropogenic influence, but rather by internal coupled ocean-atmosphere variability. Thus, the relative importance of the internal and forced changes in hurricane intensity in the past (Holland and Webster 2007) and future needs to be further clarified. A recent study by Camargo et al. (2014) found that the tropical cyclone PI change is a fundamental indicator for tropical cyclone genesis trend, further emphasizing the importance of understanding the PI changes in the past and the future.

Additionally, anthropogenic aerosols could contribute to changes in North Atlantic hurricane potential intensity in the historical period, as well as in the future projections. Villarini and Vecchi (2013) assessed the changes in North Atlantic tropical cyclone intensity using the seasonally integrated power dissipation index (PDI) in CMIP5 model ensembles. They argue that the observed increase in PDI in the past 30 years is due to a combination of increased greenhouse gases, decreased aerosols, and the AMV. The possible role of aerosols' forcing in the observed multidecadal fluctuations in tropical North Atlantic SST has been discussed by various studies (Mann and Emanuel 2006; Evan et al. 2008, 2009; Booth et al. 2012; Zhang et al. 2013; Wilcox et al. 2013). It is not entirely clear how much of the past changes in Atlantic hurricane intensity may be attributable to greenhouse gases and aerosol forcing and how much is due to natural multidecadal variability, such as the AMV. This study takes a closer look at these different forcing mechanisms and their contribution to the historical hurricane potential intensity changes as well as the future projection of PI changes within the CMIP5 models. We use multimodel mean and S/N EOF analysis to obtain a robust signal associated with the external radiative forcing in the historical and future CMIP5 scenario simulations, as well as in the historical singleforcing simulations.

The paper is organized as follows. Following the section on data and analysis methodology, we discuss in section 3 the role of the AMV and climate change (CC) in contributing to PI changes using CMIP5's historical and two future scenarios experiments, as well as the attribution of PI changes due to all forcing, the aerosolonly, and greenhouse gas (GHG)-only forcing during the historical periods. We present the results and summary in section 4 . 
TABLE 1. List of CMIP5 models and the number of ensemble members used in this study. (Expansions for model name acronyms are available online at http://www.ametsoc.org/PubsAcronymList.)

\begin{tabular}{|c|c|c|c|c|c|c|}
\hline & Model & Historical & RCP4.5 & RCP8.5 & Aerosol & GHG \\
\hline M1 & ACCESS1.0 & 1 & 1 & 1 & - & - \\
\hline M2 & ACCESS1.3 & 1 & 1 & 1 & - & - \\
\hline M3 & BCC_CSM1.1 & 3 & 1 & 1 & - & - \\
\hline M4 & CanESM2 & 5 & 5 & 5 & 5 & 5 \\
\hline M5 & CCSM4 & 6 & 6 & 6 & - & - \\
\hline M6 & CNRM-CM5 & 10 & 1 & 5 & - & - \\
\hline M7 & CSIRO Mk3.6.0 & 10 & 5 & 10 & 5 & 5 \\
\hline M8 & FGOALS-g2 & 5 & 1 & 1 & 1 & 1 \\
\hline M9 & FIO-ESM & 3 & 3 & 3 & - & - \\
\hline M10 & GFDL CM3 & 5 & 1 & 1 & 3 & 3 \\
\hline M11 & GFDL-ESM2M & 1 & 1 & 1 & 1 & 1 \\
\hline M12 & GISS-E2-H & 5 & 5 & 1 & 5 & 5 \\
\hline M13 & GISS-E2-R & 5 & 5 & 1 & 5 & 5 \\
\hline M14 & HadGEM2-CC & 1 & 1 & 1 & - & - \\
\hline M15 & HadGEM2-ES & 4 & 1 & 4 & - & - \\
\hline M16 & INM-CM4.0 & 1 & 1 & 1 & - & - \\
\hline M17 & IPSL-CM5A-LR & 5 & 4 & 4 & 1 & 3 \\
\hline M18 & IPSL-CM5B-LR & 1 & 1 & 1 & - & - \\
\hline M19 & IPSL-CM5A-MR & 1 & 1 & 1 & - & - \\
\hline M20 & MIROC5 & 4 & 1 & 3 & - & - \\
\hline M21 & MIROC-ESM & 3 & 1 & 1 & - & - \\
\hline M22 & MIROC-ESM-CHEM & 1 & 1 & 1 & - & - \\
\hline M23 & MPI-ESM-LR & 3 & 3 & 3 & - & - \\
\hline M24 & MPI-ESM-MR & 3 & 3 & 1 & - & - \\
\hline M25 & MRI-CGCM3 & 3 & 1 & 1 & - & - \\
\hline M26 & NorESM1-M & 3 & 1 & 1 & 1 & 1 \\
\hline Total & & 93 & 56 & 60 & 27 & 29 \\
\hline
\end{tabular}

\section{Data and analysis methodology}

We used 26 CMIP5 models (see Table 1) for the hurricane potential intensity analysis in this study, which includes 93 ensemble members for the historical simulations. The historical simulations are forced with observed atmospheric composition changes (natural and anthropogenic), as well as time-evolving land cover. A complete description of the various CMIP5 scenarios and models can be found in Taylor et al. (2012). For the future scenarios, we consider two representative concentration pathways (RCPs): a midrange mitigation scenario, RCP4.5, and a high emission scenario, RCP8.5, corresponding to radiative forcing values of 4.5 and $8.5 \mathrm{~W} \mathrm{~m}^{-2}$ by the end of the twenty-first century, respectively. We analyzed the same 26 CMIP5 model ensembles for the future scenarios with 56 members for the RCP4.5 and 60 members for the RCP8.5. We also considered two additional scenarios with single forcing, the historical GHG-only and aerosols-only simulations. Because of the limited number of models that provide the historical aerosol-only simulations (9), we limited our study to the same 9 models for the analysis of aerosol-only and GHG-only simulations, with 27 and 29 total ensemble members, respectively (Table 1). For consistency, we also used the output from the same 9 models taken from the historical all-forcing integrations for comparison where appropriate. The monthly atmospheric fields from the NCEP-NCAR reanalysis (Kalnay et al. 1996; Kistler et al. 2001) and the monthly Reynolds SST (Reynolds et al. 2002) were used to calculate the monthly reanalysis PI values for the period 1971-2000.

The PI is computed from monthly mean data as in Camargo et al. (2013), using the definition developed by Bister and Emanuel in a series of papers (Emanuel 1988, 1995; Bister and Emanuel 1998, 2002a,b). The PI is defined as

$$
\mathrm{PI}=C_{k} / C_{d} T_{s} / T_{0}\left(\mathrm{CAPE}^{*}-\mathrm{CAPE}^{b}\right),
$$

where $C_{k}$ is the exchange coefficient for enthalpy, $C_{d}$ is the drag coefficient, $T_{s}$ is the sea surface temperature, and $T_{0}$ is the mean temperature at the outflow level. The convective available potential energy (CAPE) is the vertical integral of parcel buoyancy as a function of parcel temperature, pressure, and specific humidity, as well as the vertical profile of virtual temperature. The quantity CAPE* is the value of CAPE for an air parcel at the radius of maximum wind that has been lifted from a saturated state at the sea surface temperature and pressure, while $\mathrm{CAPE}^{b}$ refers to the value of CAPE calculated for the actual humidity value of the boundary 
(a) CMIP5 Historical 1971-2000

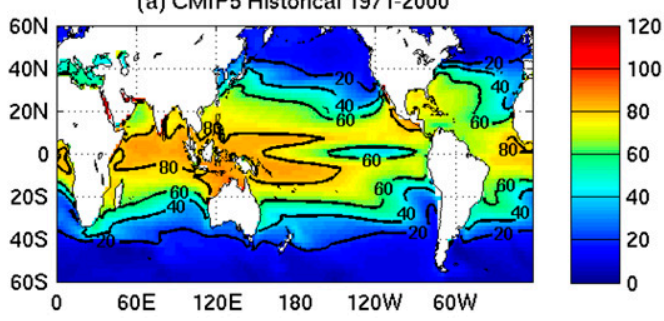

(c) CMIP5 rcp4.5 2071-2100

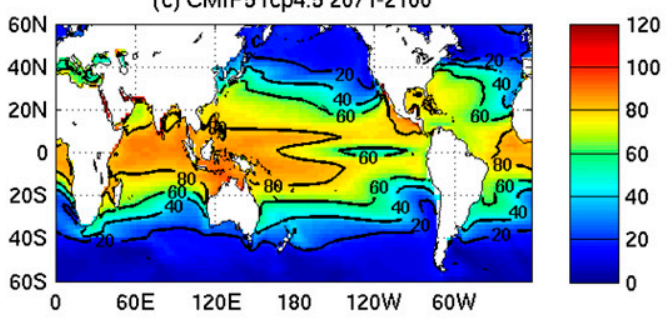

(e) Difference rcp 4.5 \& Historical

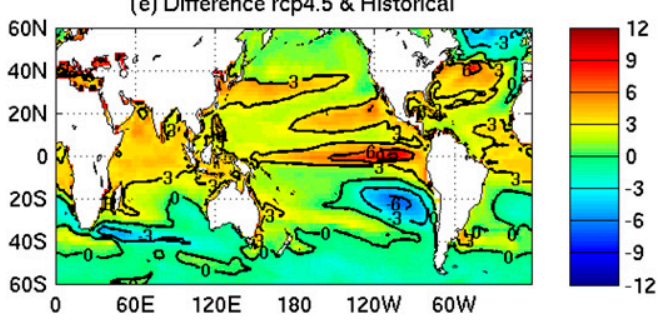

(b) NCEP Reanalysis 1971-2000

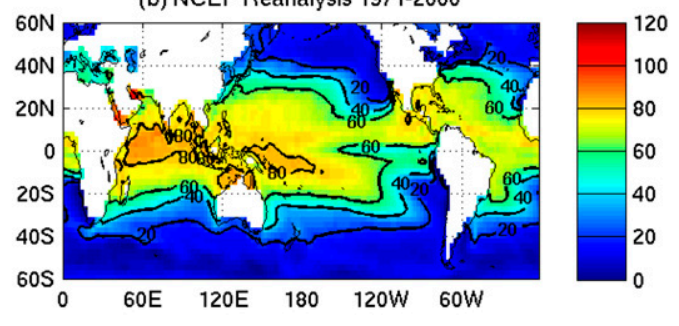

(d) CMIP5 rcp8.5 2071-2100
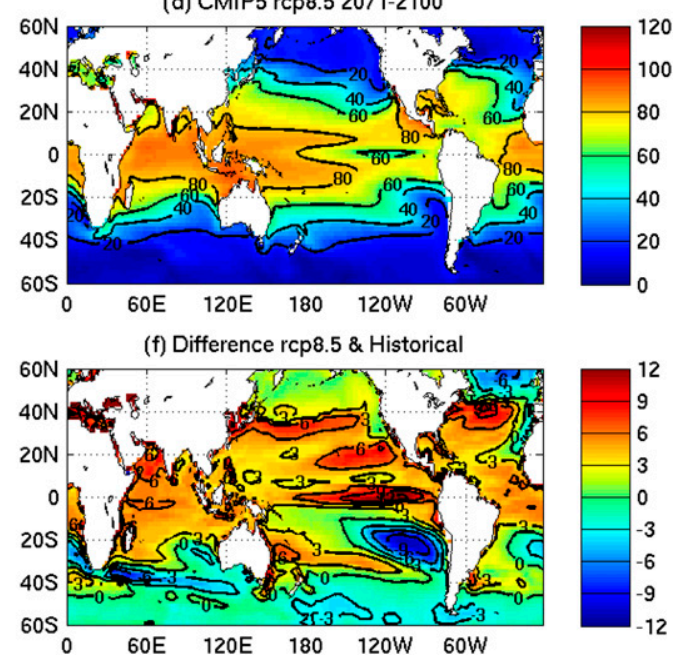

FIG. 1. Annual maximum PI ( $\mathrm{m} \mathrm{s}^{-1}$ ) in CMIP5 multimodel mean (MMM) for (a) the historical runs averaged from 1971 to 2000, (b) NCEP-NCAR reanalysis from 1971 to 2000, (c) MMM RCP4.5 from 2071 to 2100, (d) MMM RCP8.5 from 2071 to 2100, (e) the MMM difference between RCP4.5 and the historical, and (f) the difference between RCP8.5 and the historical.

layer air at the radius of maximum wind. The environmental variables necessary to calculate PI include the sea surface temperature, sea level pressure, and vertical profiles of temperature and specific humidity.

We apply signal-to-noise maximizing empirical orthogonal function analysis (Allen and Smith 1997) to the peak hurricane season [August-October (ASO)] average SSTs of the CMIP5 multimodel, multiensemble members to extract the forced signal because of the common external radiative forcing [for details, see Ting et al. (2009)]. A Butterworth low-pass filter (Butterworth 1930) with 10yr cutoff frequency is applied to the seasonal mean data prior to the S/N EOF analysis. With multimodel, multirealization CMIP5 models subject to the common external radiative forcing (i.e., historical, $\mathrm{RCP} 4.5$, and $\mathrm{RCP} 8.5$ ), the total covariance matrix of the ensemble mean SST may be expressed as the sum of two linearly independent matrices: one for the forced component and one for the internal variability or climate noise. The spatial structure of the noise modes was determined from the long preindustrial integrations corresponding to each of the CMIP5 models and used in the spatial prewhitening transformation to remove the climate noise from the ensemble mean covariance matrix. The first S/N EOF mode (EOF1) and its associated principal component (PC1) were taken as the dominant forced variability. Once we obtained the $\mathrm{S} / \mathrm{N}$ PC1, we applied a linear regression to obtain the spatial structure of the variables associated with the forced component of the SST and the PI.

\section{Results}

\section{a. Changes in North Atlantic potential intensity as simulated in CMIP5 models}

To examine the change in tropical storm potential intensity due to both anthropogenic forcing and internal SST variability in CMIP5 models, we first compare the PI from the CMIP5 historical simulations to that calculated from the reanalysis. Figure 1a shows the annual maximum PI for CMIP5 historical multimodel mean for the period 1971-2000 as compared to the NCEP-NCAR reanalysis for the same period (Fig. 1b). There is a general agreement between the CMIP5 historical simulations and observations, with the largest PI reaching above $80 \mathrm{~m} \mathrm{~s}^{-1}$ in the tropical western Pacific and the Indian Ocean. Local PI maxima are also found over the 
(a) PI ASO Clim Hist

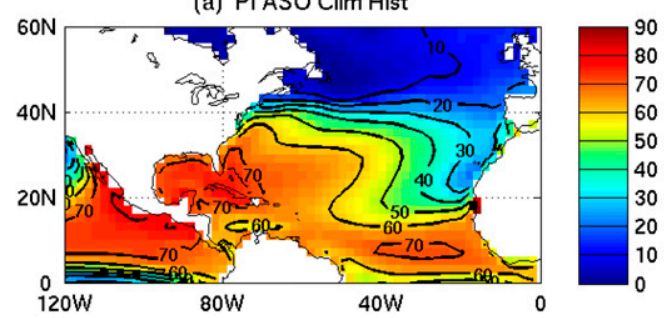

(c) PI ASO Diff. rcp4.5 \& Hist.

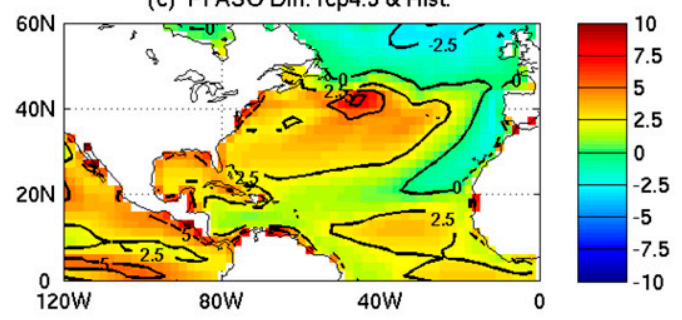

(e) PI ASO Diff. rcp8.5 \& Hist.

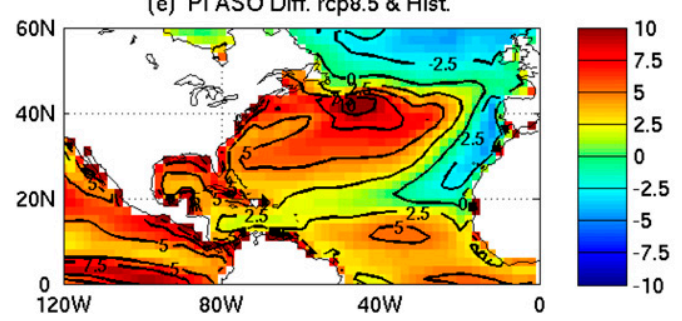

(b) SST ASO Clim Hist

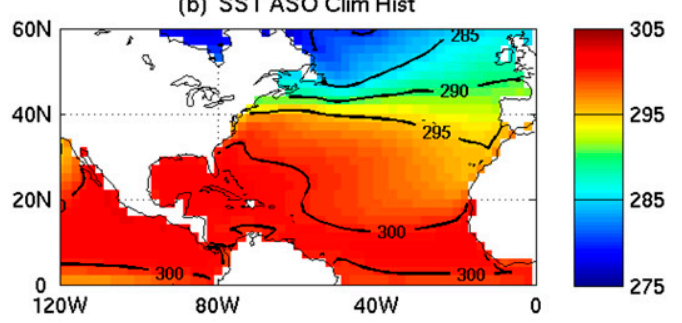

(d) SST ASO Diff. rcp4.5 \& Hist.

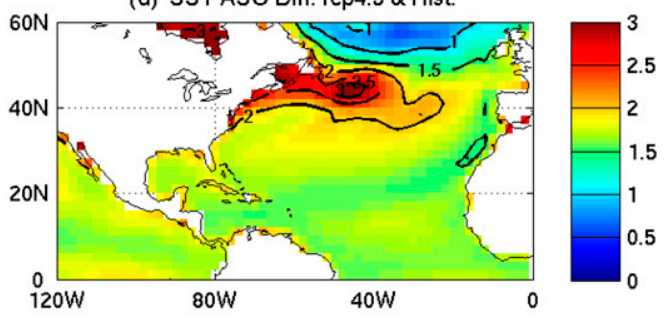

(f) SST ASO Diff. rcp8.5 \& Hist.

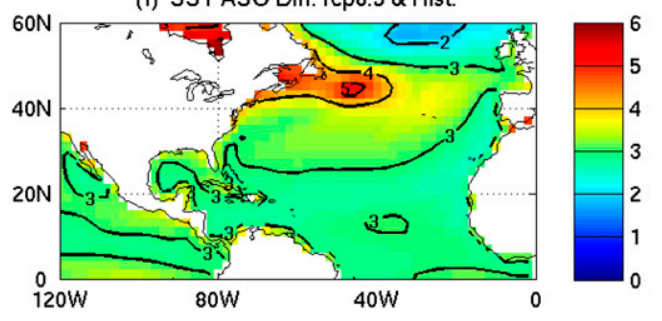

FIG. 2. Climatological distribution of the ASO seasonal mean (left) PI $\left(\mathrm{m} \mathrm{s}^{-1}\right)$ and (right) SST $\left({ }^{\circ} \mathrm{C}\right)$ in multimodel average for (a) the historical CMIP5 model runs averaged over the years 1971-2000, (b) difference between RCP4.5 for 2071-2100 and the historical CMIP5 MMM, and (c) difference between RCP8.5 for 2071-2100 and the historical CMIP5 MMM.

eastern Pacific off the west coast of Mexico and over the tropical Atlantic, extending from the Gulf of Mexico and the southeast coast of the United States to the Gulf of Guinea in both model and observations. The annual maximum PI for RCP4.5 and RCP8.5 averaged from 2071 to 2100 is shown in Figs. 1c and 1d, respectively, with the corresponding difference between the RCP4.5 and RCP8.5 scenarios and the historical simulations shown in Figs. 1e and 1f, respectively. The spatial patterns of the PI projected by the models for the late twenty-first century are very similar to those in the historical runs, with the regions of the largest PI expanded and intensified in the twenty-first century. This expansion is clearly seen in the difference maps (Figs. 1e and 1f), which show a general increase in PI across the tropical domain and most of the Northern Hemisphere in the future scenario simulations. The largest increase reaches $3 \mathrm{~m} \mathrm{~s}^{-1}$ in RCP 4.5 and $6 \mathrm{~m} \mathrm{~s}^{-1}$ in RCP 8.5 over the Indian Ocean and the eastern tropical Pacific, and slightly less in the tropical Atlantic. ${ }^{1}$ In the rest of this paper, we

\footnotetext{
${ }^{1}$ Differences of PI for RCP8.5 and historical simulations for 14 individual CMIP5 models can be seen in Fig. 13 of Camargo (2013).
}

focus our attention mainly over the North Atlantic domain and the CMIP5 models.

The North Atlantic PI climatology for the peak hurricane season of ASO for multimodel and multiensemble mean averaged over the late twentieth century, from 1971 to 2000, is shown in Fig. 2a. The pattern of PI follows closely that of the multimodel mean SST (Fig. 2b), with maximum PI located over the Gulf of Mexico and the Caribbean as well as the tropical Atlantic between the equator and $15^{\circ} \mathrm{N}\left(>70 \mathrm{~m} \mathrm{~s}^{-1}\right)$. This pattern is qualitatively similar to that calculated from the observations based on the reanalysis (see Fig. 1b and Fig. 3 in Camargo et al. 2013). Figures $2 \mathrm{c}$ and $2 \mathrm{e}$ show the model-projected change in PI from the late twentieth century in the RCP4.5 and RCP8.5 simulations for the period 20712100. According to the models and under the forcing scenarios specified, the PI will increase over most of the tropical Atlantic Ocean, with the only exception along the North African coast, where PI decreases. The pattern of PI changes follows that of the SST change, with the region of negative PI change corresponding to the region of relatively weak SST warming (Figs. 2d,f). The increase in PI over the Atlantic is the strongest in the western North Atlantic, extending from the Gulf of Mexico to the 


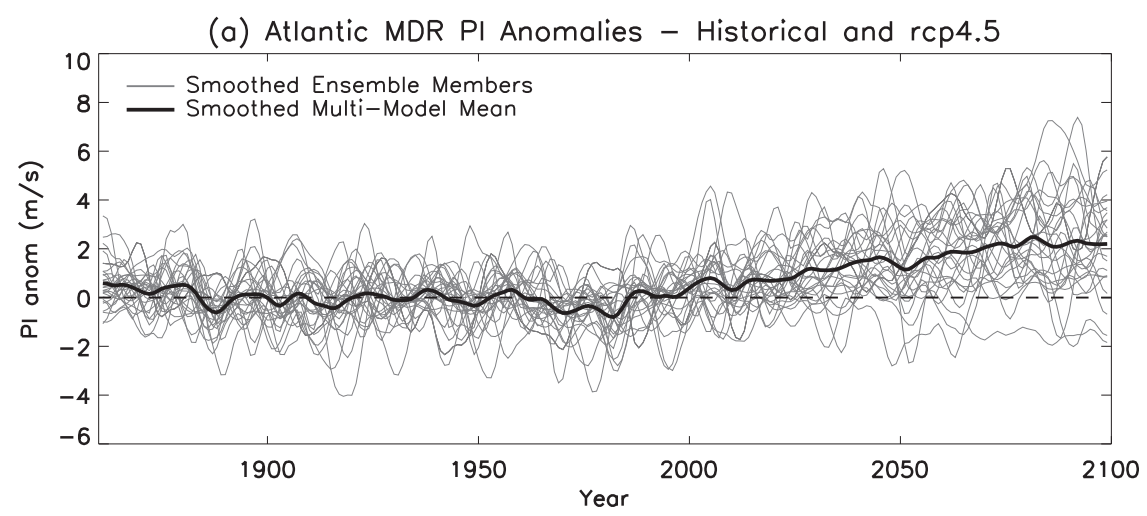

(b) Atlantic MDR PI Anomalies - Historical and rcp8.5

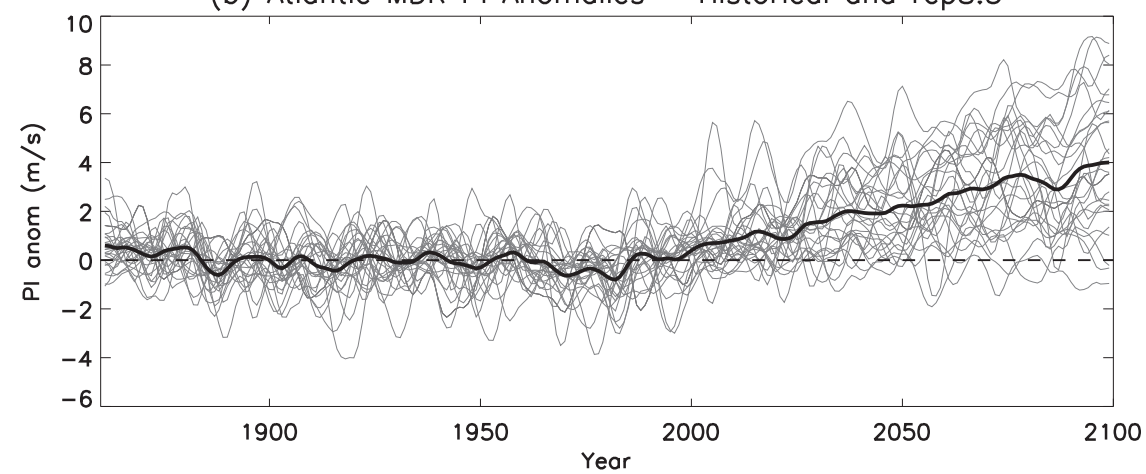

FIG. 3. The MDR $\left(10^{\circ}-20^{\circ} \mathrm{N}, 20^{\circ}-85^{\circ} \mathrm{W}\right.$; see gray box in Fig. 5) domain-averaged PI anomaly $\left(\mathrm{m} \mathrm{s}^{-1}\right)$ from 1850 to 2100 for CMIP5 (a) historical (1850-2005) + RCP4.5 (2006-2100) and (b) historical (1850-2005) + RCP8.5 (2006-2100) simulations. The PI anomalies are defined as the deviation from the long-term average for the historical period, 1861-2005. Thin gray lines represent the PI for one ensemble member each from the 26 CMIP5 models, subject to the Butterworth filter with the cutoff frequency of $10 \mathrm{yr}$, and the thick black line is for the multimodel ensemble mean based on one ensemble member from each model.

U.S. East Coast from Florida to New England. The large PI anomalies along the Gulf and East Coasts of the United States in Figs. $2 \mathrm{c}$ and 2e indicate a potential threat of stronger hurricane tracking along the U.S. Atlantic coasts south of $30^{\circ} \mathrm{N}$. North of $30^{\circ} \mathrm{N}$, hurricanes tend to go through extratropical transition, and the PI may not be a good measure of the storm intensity. The east-west pattern of PI and SST changes in Fig. 2 is consistent with ocean-atmosphere interactions resulting from an enhanced North Atlantic subtropical anticyclone in summer (e.g., Li et al. 2012), which increases the coastal upwelling along the western European and African coasts and enhances the warm water advection along the western basin.

The temporal evolution of the PI intensity change throughout the twentieth and twenty-first century, as simulated by the first ensemble member of each CMIP5 model (thin gray lines), is depicted in Fig. 3, which shows the domain-averaged PI anomalies (with respect to the 1861-2005 climatology) in the hurricane main development region $\left(10^{\circ}-20^{\circ} \mathrm{N}\right.$ and $20^{\circ}-85^{\circ} \mathrm{W}$; see gray box in Fig. 5). Each PI time series in Fig. 3 has been subjected to the Butterworth filter with a cutoff frequency of $10 \mathrm{yr}$ to retain only the decadal and longer time scale fluctuations. The multimodel mean is shown in a thick black line. We use one ensemble member each in Fig. 3 rather than all available ensemble members to avoid biasing the result toward models with a large number of ensemble members. By the end of the twenty-first century, the ensemble of CMIP5 models projects an increase of slightly over 2 and $4 \mathrm{~m} \mathrm{~s}^{-1}$ for the RCP4.5 and RCP8.5 scenarios, respectively. Thus, Fig. 3 suggests that in the future, the anthropogenic greenhouse effect will likely lead to more intense North Atlantic hurricanes in the MDR region. The averaged PI over the entire tropical North Atlantic domain (not shown), which covers the Gulf of Mexico and the U.S. East Coast, shows a slightly larger increase in PI at the end of the twenty-first century, consistent with Figs. 2c and 2d.

Figure 3 exhibits large amplitude fluctuations in each ensemble member PI around the multimodel mean. These are due both to decadal and longer time scale natural variability of the PI in each model run and to the 
(a) SST S/N EOF1 Spatial Pattern (CMIP5/Hist)

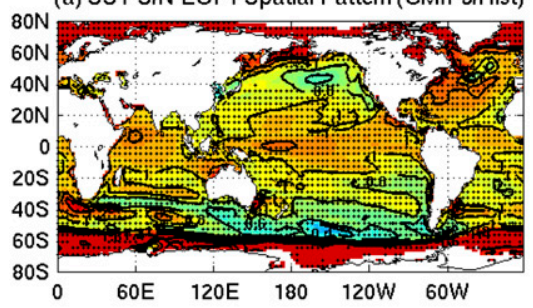

(c) SST S/N EOF1 Spatial Pattern (CMIP5/rcp4.5)

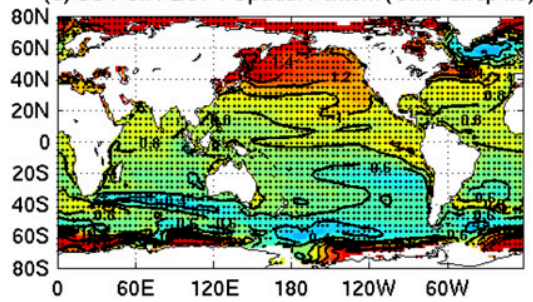

(e) SST SIN EOF1 Spatial Pattern (CMIP5/rcp8.5)

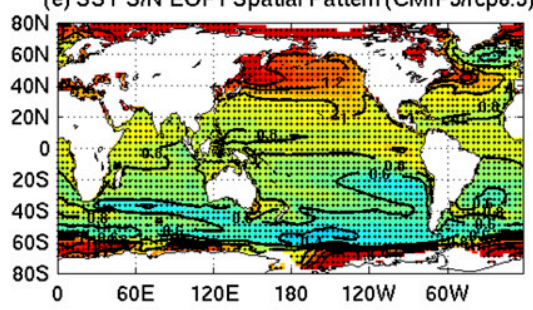

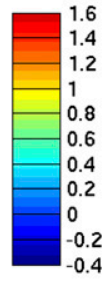
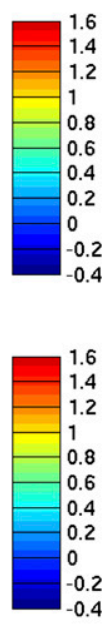

(b) SST S/N EOF PC1

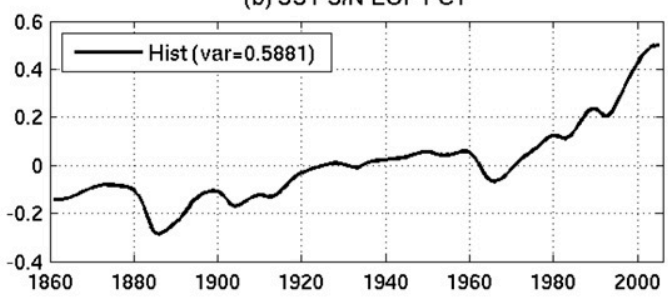

(d) SST S/N EOF PC

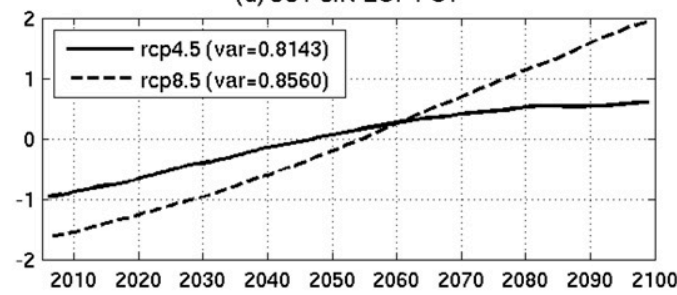

(f) AMV Indices (Observations \& CMIP5/Hist)

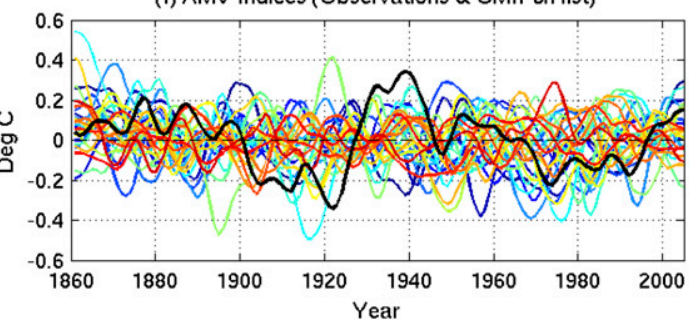

FIG. 4. (a),(c),(e) EOF1 spatial patterns and (b),(d) principal components of the multimodel S/N maximizing EOF analysis for the (a),(b) historical and (c),(d),(e) the two RCP scenarios. (f) The AMV indices from one ensemble each of the 26 historical CMIP5 models (colored lines) and observations (black line).

model spread in response to external radiative forcing changes. By removing the climatological mean PI from 1861 to 2005 in each model, the model biases were largely removed for the twentieth century, and the individual model's PI fluctuations reflect mostly the internal decadal-to-multidecadal fluctuations in Fig. 3. Toward the end of the twenty-first century, however, the large spread in the individual model's MDR PI is partly caused by the different sensitivity of the CMIP5 models to the anthropogenic forcing. The amplitude of the internal decadal and longer PI fluctuations, which is approximately between -2 and $+2 \mathrm{~ms}^{-1}$ around the multimodel mean for the twentieth century, is relatively unchanged in the twenty-first century (see further discussion in section $3 b$ ). Figure 3 shows that the internal decadal and longer PI fluctuations are comparable to the end of the century multimodel mean PI increases. By the year 2020, the anthropogenic PI increases will be large enough in the RCP8.5 scenario that only very few ensemble members would have their PI below the climatological mean of the twentieth century.

In the next subsection, we examine in detail the relative amplitude and spatial patterns of the forced and AMV-related PI changes in CMIP5 models.

\section{b. PI changes associated with AMV and climate change in CMIP5 models}

To obtain the spatial and temporal patterns of the forced and internal multidecadal variability in the CMIP5 models' historical, RCP4.5, and RCP8.5 simulations, we performed signal-to-noise maximizing EOF analysis on global SST following Ting et al. (2009) for the ASO hurricane season to determine the externally forced component of the global SST. The spatial patterns and principal components of the first S/N EOF mode for historical, RCP4.5, and RCP8.5 simulations are shown in Fig. 4, based on multimodel and multiensemble member CMIP5 simulations. The first mode explains a large fraction of the total forced variance (59\% for historical, $81 \%$ for RCP4.5, and $86 \%$ for RCP8.5) and thus can be used to represent the dominant pattern of SST response to the prescribed external forcing applied in these models, including timevarying greenhouse gas and aerosol concentrations, solar variations, and volcanic eruptions. The spatial structures associated with the external forcing for the ASO season are consistent with previous results, showing a general warming everywhere except the northern North Atlantic and Southern Oceans (Meehl et al. 1996; Russell and Rind 
(a) AMO Reg. Hist. Multi-model Mean

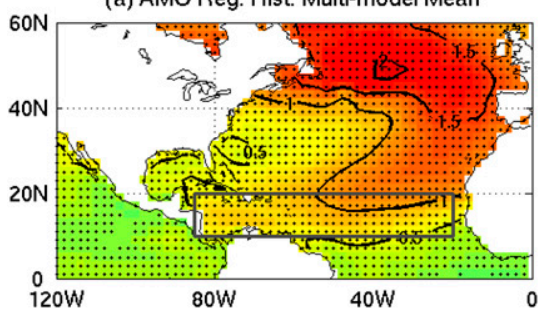

(c) AMO Reg. rcp4.5 Multi-model Mean

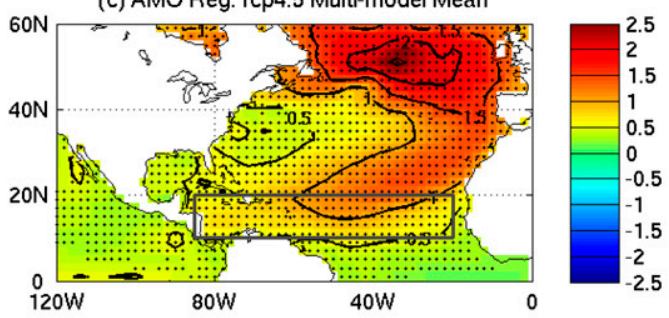

(e) AMO Reg. rcp8.5 Multi-model Mean

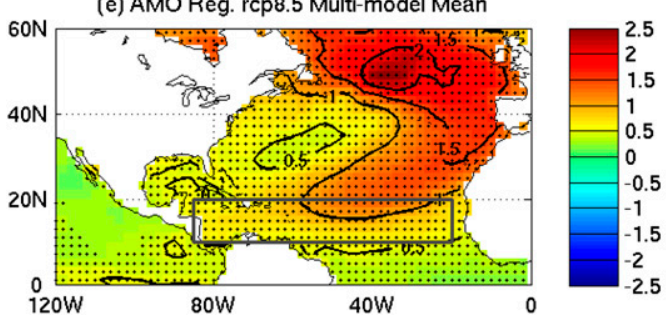

(b) CC Reg. Hist. Multi-model Mean

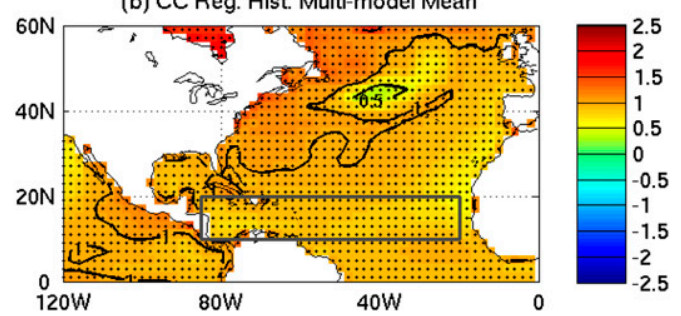

(d) CC Reg. rcp4.5 Multi-model Mean

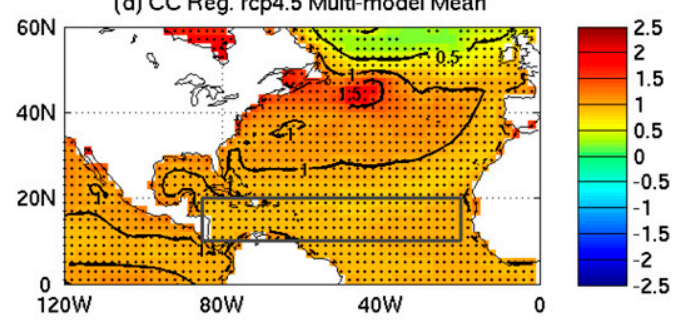

(f) CC Reg. rcp8.5 Multi-model Mean

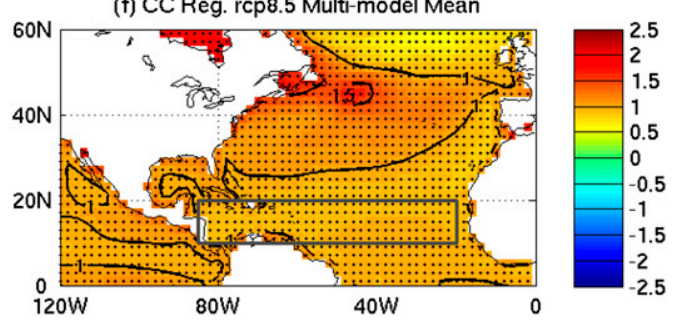

FIG. 5. SST regression onto (left) AMV index and (right) climate change index for MMM CMIP5 (a),(b) historical, (c),(d) RCP4.5, and (e)(f) RCP8.5 (unit: degree of SST per degree of SST index). The gray box indicates the MDR region. Stippling indicates 20 out of 26 models' agreement in the sign of the regression coefficients.

1999; Wood et al. 1999). The S/N PC1 exhibits almost monotonic increase in time, with the historical one having some decadal fluctuations, possibly associated with volcanic eruptions and changes in anthropogenic aerosol concentrations (Evan et al. 2008, 2009; Bellouin et al. 2011; Chang et al. 2011; Booth et al. 2012; Zhang et al. 2013).

For each model ensemble member, we removed the forced SST component year by year at each grid point by regressing out the projection on $\mathrm{S} / \mathrm{N}$ PC1 (referred to herein as $\mathrm{CC}$ ). The residual SST time series averaged in the North Atlantic domain $\left(0^{\circ}-60^{\circ} \mathrm{N}\right)$ represents the AMV time series [see Ting et al. (2011) for details]. The resulting AMV indices are shown in Fig. 4f for one member each of the CMIP5 models' historical simulations along with the corresponding observed time series (in black). As discussed in Ting et al. (2009) and Ting et al. (2011), the inferred period of the AMV "oscillation" in coupled climate models varies greatly from one model to another, ranging from approximately $20 \mathrm{yr}$ to the observed period $(\sim 70 \mathrm{yr})$. Figure 5 shows the multimodel mean SST spatial pattern corresponding to the AMV (Figs. 5a,c,e) and the CC (Figs. 5b,d,f) components.
In calculating these patterns, each ensemble member's SST is first regressed onto the corresponding AMV index and the multimodel CC index. The ensemble mean pattern for each model is obtained next, and finally the multimodel mean is computed by averaging across all 26 ensemble mean regression patterns. The stippling in Fig. 5 indicates that at least 20 out of 26 models agree in the signs of the regression coefficients in that location. The SST patterns associated with AMV (Figs. 5a,c,e) are consistent with that shown in Ting et al. (2011) based on the CMIP3 multimodel mean, with comma-shaped SST anomalies extending from the south of Greenland along the eastern Atlantic basin toward the tropical Atlantic. The CMIP5 AMV SST patterns are relatively insensitive to the radiative forcing strength that ranges from historical forcing to RCP8.5 in Fig. 5, consistent with Ting et al. (2011). The SST patterns associated with the CC index (Figs. 5b,d,f) are substantially different from those of AMV, with maximum warming centered in the middle of the North Atlantic. The externally forced SST patterns in Figs. $5 b, 5 d$, and $5 f$ are also qualitatively similar to Figs. $2 d$ and $2 \mathrm{f}$, which are the multimodel mean SST difference between the last 30 years of the twenty-first century from 
(a) AMO Reg. Hist. Multi-model Mean

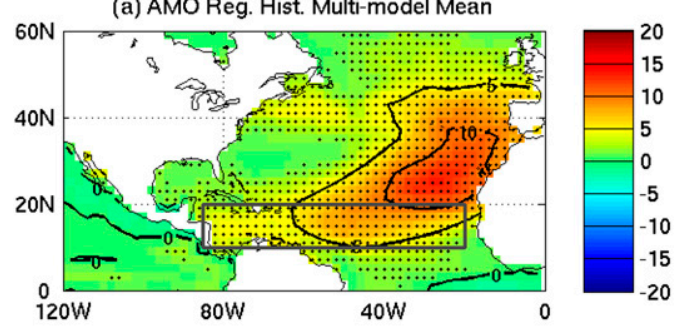

(c) AMO Reg. rcp4.5 Multi-model Mean

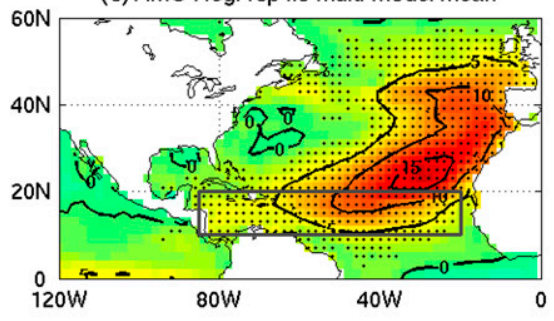

(e) AMO Reg. rcp8.5 Multi-model Mean

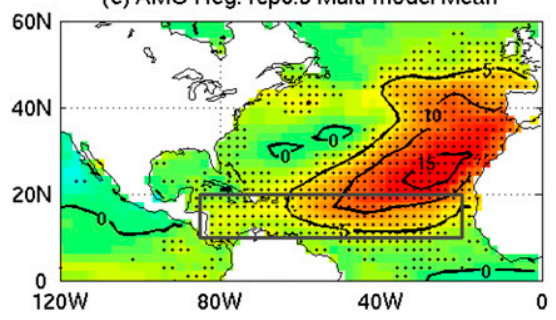

(b) CC Reg. Hist. Multi-model Mean

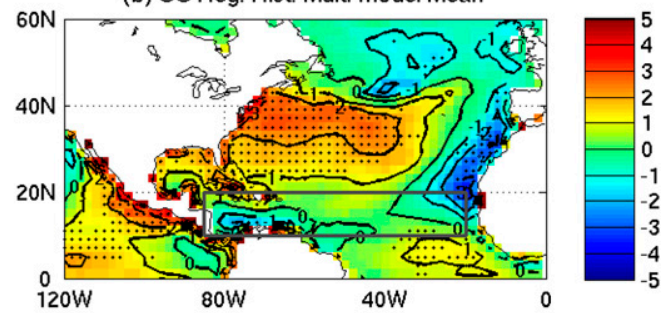

(d) CC Reg. rcp4.5 Multi-model Mean

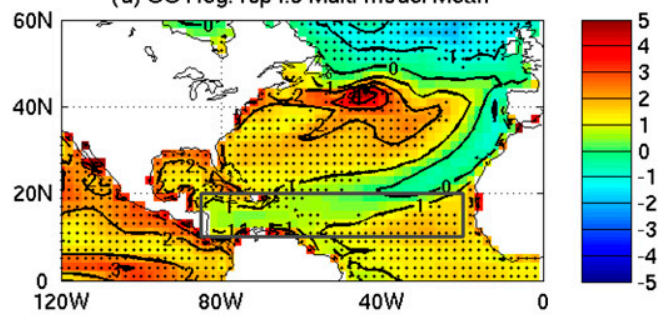

(f) CC Reg. rcp8.5 Multi-model Mean

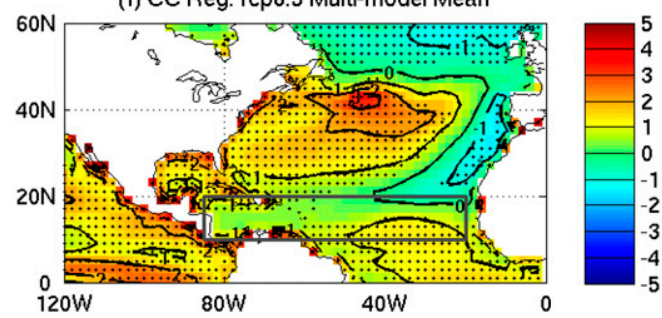

FIG. 6. Regression of ASO PI onto (left) AMV and (right) CC indices (unit: $\mathrm{m} \mathrm{s}^{-1}$ per degree of SST index). The gray box indicates the MDR region. Stippling indicates 20 out of 26 models' agreement in the sign of the regression coefficients.

that of the twentieth century. The robustness of the SST changes associated with both AMV and CC is implied by the high degree of agreement among the 26 models, as indicated by the stippling across the entire North Atlantic domain.

The corresponding regression patterns for the hurricane PI are shown in Fig. 6. The PI associated with AMV shows the maximum amplitude along the eastern side of the North Atlantic basin, with little amplitude on the western side of the Atlantic basin along the U.S. Gulf and East Coasts. The maximum amplitude is located at around $20^{\circ} \mathrm{N}$. As is the case for SST, the model PI spatial patterns associated with AMV are relatively insensitive to the radiative forcing strength and are robust across models. The PI patterns associated with CC (Figs. 6a,c,e) show almost opposite patterns to that of AMV, with the largest amplitude in the Gulf of Mexico and the western basin of the North Atlantic between $20^{\circ}$ and $40^{\circ} \mathrm{N}$. Along the west coast of Africa, the PI changes are generally negative because of a relative weak warming there (see Fig. 5). The models are less robust in terms of the signs of the regression coefficients corresponding to $\mathrm{CC}$ index over the MDR region (gray box) in Figs. 6b, 6d, and 6e, particularly in the historical forcing simulations. These disagreements among different CMIP5 models in PI change because climate change over the MDR region may be caused by the relatively weak SST warming in the region due to local ocean dynamics, which led to a relatively small change in the PI. This will be further discussed in terms of PI amplitude below.

Figures 5 and 6 only show the spatial patterns of SST and PI associated with AMV and CC. To determine the actual amplitude changes, we computed the root-mean-square (rms) amplitude of SST and PI associated with AMV and $\mathrm{CC}$ over the MDR region. Figure 7 shows the box-andwhiskers diagram of the MDR SST and PI rms amplitude associated with AMV and CC, based on the first ensemble member from each of the 26 CMIP5 models (Table 1). The results in Fig. 7 are qualitatively similar when all ensemble members or ensemble average amplitude for each model was used instead of using a single member for each model. The mean AMV SST amplitude (asterisks in Fig. 7a) is relatively insensitive to the external radiative forcing strength exhibiting a range between $0.06^{\circ}$ and $0.08^{\circ} \mathrm{C}$. However, the SST amplitude associated with CC increases as the forcing strength increases, as expected, from $0.17^{\circ} \mathrm{C}$ in the historical period to $0.41^{\circ} \mathrm{C}$ in $\mathrm{RCP} 4.5$ and $0.93^{\circ} \mathrm{C}$ in RCP8.5 scenarios. For the PI (Fig. 7b), 
(a) RMS of MDR SST (CMIP5)

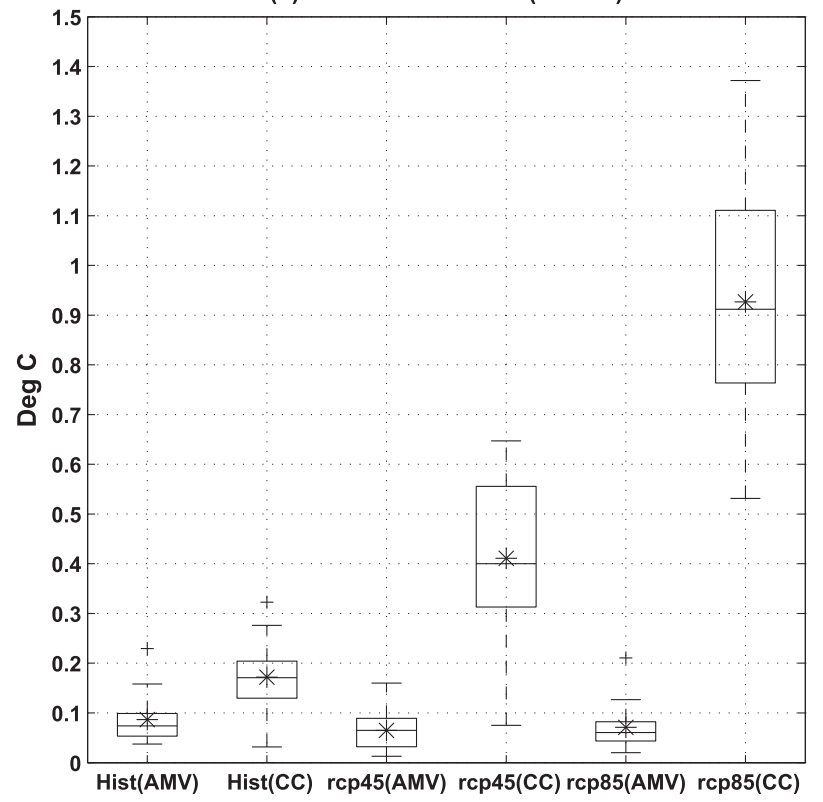

(b) RMS of MDR PI (CMIP5)

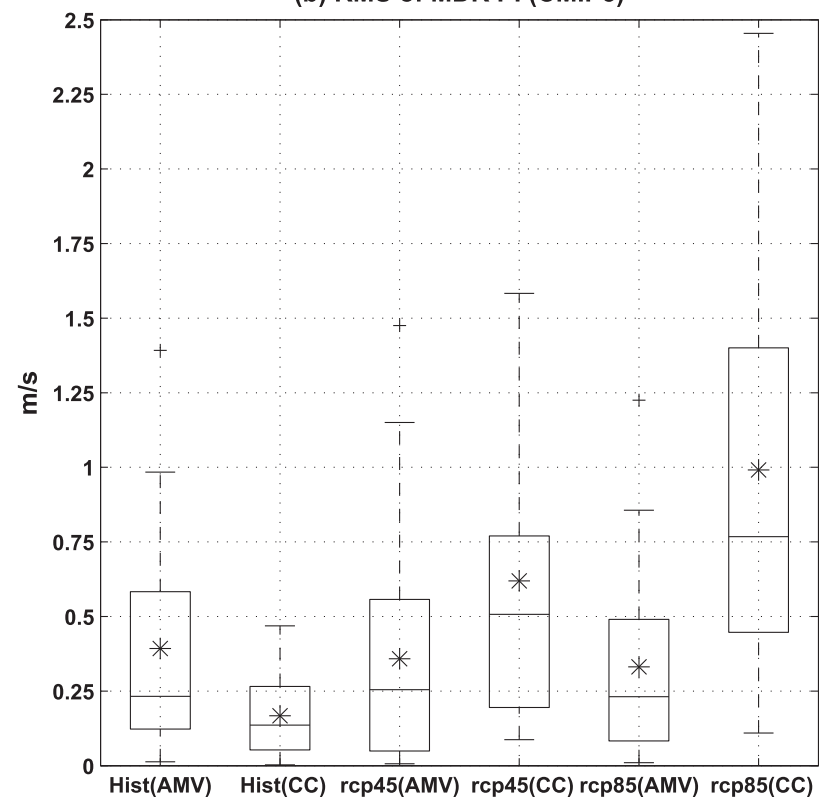

FIG. 7. Box-and-whiskers diagram for the (a) MDR SST $\left({ }^{\circ} \mathrm{C}\right)$ and $(\mathrm{b})$ potential intensity $\left(\mathrm{m} \mathrm{s}^{-1}\right)$ associated with the AMV and the CC indices using the first member of each CMIP5 models' historical, RCP4.5, and RCP8.5 simulations, as indicated along the abscissa. Box edges depict the middle $50 \%(25 \%-75 \%)$ of the data points, the lines inside the boxes depict the median, and asterisks depict the mean values; whiskers include \pm 2.7 std $\operatorname{dev}(\sim 0.35 \%-99.65 \%)$ of the data points, and pluses indicate the outliers.

the mean PI amplitude associated with AMV fluctuates slightly from $0.39 \mathrm{~m} \mathrm{~s}^{-1}$ in historical runs to $0.34 \mathrm{~m} \mathrm{~s}^{-1}$ in RCP8.5, while the PI amplitude associated with CC increases from a relatively small value in the historical simulations $\left(0.17 \mathrm{~m} \mathrm{~s}^{-1}\right)$ to about $1 \mathrm{~m} \mathrm{~s}^{-1}$ in RCP8.5. Note that the rms amplitude here differs from the actual PI increases shown in Fig. $3\left(\sim 2 \mathrm{~m} \mathrm{~s}^{-1}\right.$ for RCP4.5 and $\sim 4 \mathrm{~m} \mathrm{~s}^{-1}$ for $\mathrm{RCP} 8.5$ ). This is because the rms amplitude is a measure of the average amplitude fluctuations throughout the time period. The rms amplitude is used here for easy comparison to the amplitude associated with the AMV.

It is interesting to note in Fig. 7 that while the mean SST amplitude in the historical case associated with CC $\left(0.17^{\circ} \mathrm{C}\right)$ is larger than that for $\mathrm{AMV}\left(0.08^{\circ} \mathrm{C}\right)$, the mean PI amplitude associated with $\mathrm{CC}\left(0.17 \mathrm{~m} \mathrm{~s}^{-1}\right)$ is smaller than that for AMV $\left(0.39 \mathrm{~m} \mathrm{~s}^{-1}\right)$. This indicates that the AMVassociated MDR SST anomalies may be more effective in causing the PI changes than the corresponding one for CC. Additionally, the increase in CC-related SST changes from historical to RCP8.5 is much faster than the corresponding CC-related PI changes in Fig. 7, which indicates further that CC-related SST change may not be a good indication of the corresponding PI changes. To examine the effectiveness of the PI change given the same local SST change, we list in Table 2 the ratio of PI to SST (PI/SST) for all cases for the median (boldface) as well as the middle $50 \%$ ranges. The median values for the AMV PI change per degree of MDR SST change range from 3 to
5 times larger than the corresponding ratio for $\mathrm{CC}$. The fact that the AMV-related SST is more effective in relating to PI changes than that for CC is consistent with the results of Emanuel and Sobel (2013). Using a singlecolumn model coupled to a slab ocean, Emanuel and Sobel (2013) examined the sensitivity of tropical precipitation and other tropical cyclone-related quantities, including the PI, to SST increases induced by radiative forcing and surface wind changes. They showed that the rate of PI change as a function of SST change depends strongly on the forcing. When the SST warming is forced by solar radiation or $\mathrm{CO}_{2}$ increase, the rate of PI increase is slower than that when the SST warming is caused by surface wind reduction (see their Fig. 2b for details). To the extent that the model AMV SST in the MDR region is a result of the change in surface wind

TABLE 2. The median (boldface), $25 \%$, and $75 \%$ values of the ratio between the MDR PI and SST for historical, RCP4.5, and RCP8.5 simulations based on all ensemble members, for both AMV and CC (unit: $\mathrm{m} \mathrm{s}^{-1}$ per degree of SST).

\begin{tabular}{lcccc}
\hline \hline & & Historical & RCP4.5 & RCP8.5 \\
\hline AMV & $25 \%$ & 1.9414 & 1.1263 & 1.9469 \\
& $\mathbf{5 0} \%$ & $\mathbf{3 . 9 2 9 5}$ & $\mathbf{4 . 1 9 7 4}$ & $\mathbf{3 . 6 5 1 3}$ \\
& $75 \%$ & 6.2901 & 8.4434 & 6.2211 \\
CC & $25 \%$ & 0.3018 & 0.4825 & 0.4590 \\
& $\mathbf{5 0} \%$ & $\mathbf{0 . 7 4 4 0}$ & $\mathbf{1 . 2 5 2 2}$ & $\mathbf{0 . 9 7 7 3}$ \\
& $75 \%$ & 1.6086 & 1.9293 & 1.2986 \\
\hline
\end{tabular}




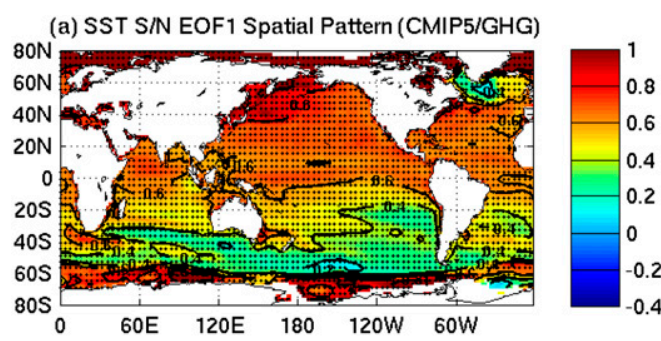

(c) SST S/N EOF PC1 (ASO) variance $=0.8683$

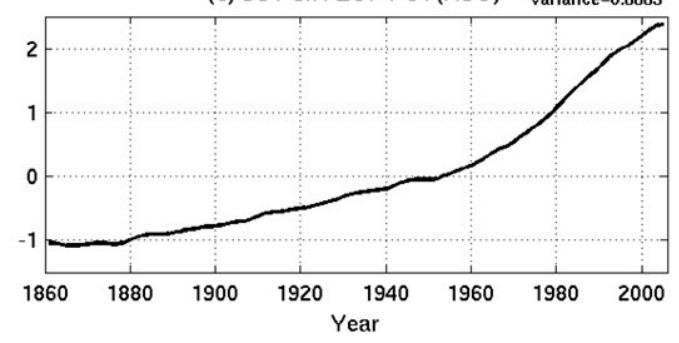

(b) SST S/N EOF1 Spatial Pattern (CMIP5/Aerosol)

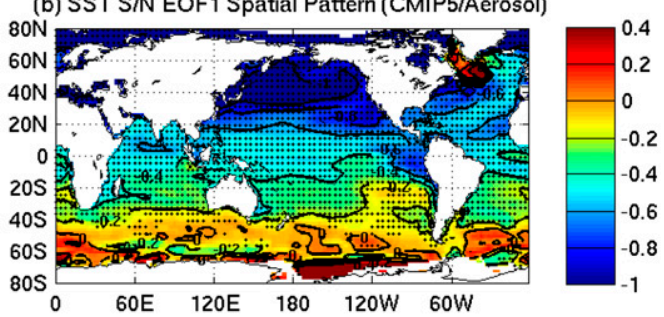

(d) SST S/N EOF PC1 (ASO) variance $=0.7315$

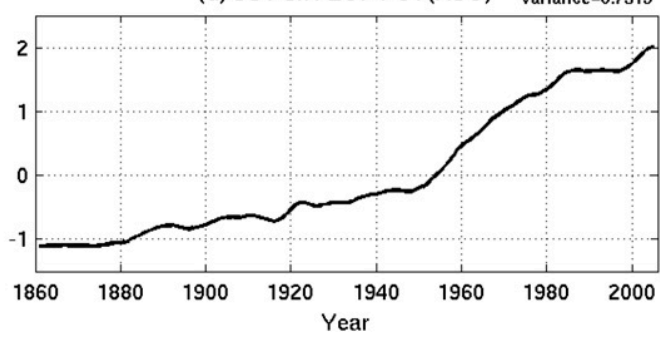

FIG. 8. S/N EOF and PC1 for the (left) greenhouse gas-only and (right) aerosol-only forcing.

(Ting et al. 2014), the PI would increase more rapidly as a function of the AMV SST than as a function of the radiatively forced SST. Table 2 is also consistent with previous findings that the local SST changes may not be a good indicator for PI changes, as it is influenced by remote SST through changes in upper-tropospheric (outflow) temperatures (e.g., Vecchi and Soden 2007; Camargo et al. 2013).

Although PI changes more rapidly with AMV SST than with radiatively forced SST, the amplitude of the SST increase due to anthropogenic warming in CMIP5's RCP4.5 and RCP8.5 scenario simulations eventually dominates the PI change during the twenty-first century. Figure $7 \mathrm{~b}$ shows that the model PI amplitude due to climate change is larger than the corresponding amplitude due to AMV at the end of the twenty-first century, particularly for the large-forcing scenario (RCP8.5). Even though there is a large spread in the PI amplitude change based on each individual model and individual ensemble member, as shown in Fig. 7b, the majority of the models show a clear separation between the RCP8.5 PI amplitude and that of the AMV PI fluctuations. Thus CMIP5 model projections indicate that the MDR PI increase due to anthropogenic warming will emerge above the level of internal decadal variability by the middle of the twenty-first century.

\section{c. The role of aerosol versus greenhouse gas forcing}

Several recent studies argued that the observed multidecadal variability in the Atlantic domain has been partly associated with aerosol forcing (e.g., Mann and Emanuel 2006; Evan et al. 2008, 2009; Booth et al. 2012). Here, we address the question of whether the aerosol-forced PI changes share similar characteristics with the PI pattern associated with AMV. There have been substantial increases in the hurricane power dissipation index since the 1970s (Emanuel 2005; Villarini and Vecchi 2013). Villarini and Vecchi (2013) attributed the increase in PDI to decreasing aerosol forcing, increasing greenhouse gas forcing, and an upward swing in AMV. It is important to attribute the historical changes of the PI to the various components mentioned above. For this purpose, we used the nine CMIP5 models that provide single-forcing historical simulations for aerosol and greenhouse gases (indicated in Table 1) in this section to examine the change in PI due to each mechanism.

The $\mathrm{S} / \mathrm{N}$ maximizing EOF is performed on the global SST for the peak Atlantic hurricane season (ASO) using nine models with aerosol-only and GHG-only forcing for the CMIP5 historical period (1860-2005), and Fig. 8 shows the first EOF pattern and the corresponding principal component time series. The models exhibit a general warming pattern corresponding to the GHGonly forcing and a cooling in the case of aerosol-only forcing, with both of the patterns intensifying throughout the historical period. This first S/N EOF mode explains $90 \%$ of GHG-only and $74 \%$ of the aerosol-only forced variance. The fact that spatial patterns of the global SST S/N EOF1 are largely opposite in sign for aerosol-only and GHG-only forcing is consistent with the results of Xie et al. (2013). The spatial pattern correlation between the two single-forcing S/N EOF1 patterns is -0.87 , also compatible with Xie et al. (2013).

The PI at each grid point in the North Atlantic basin for each ensemble member is regressed onto the corresponding PC1 time series in Fig. 8, and the multimodel 

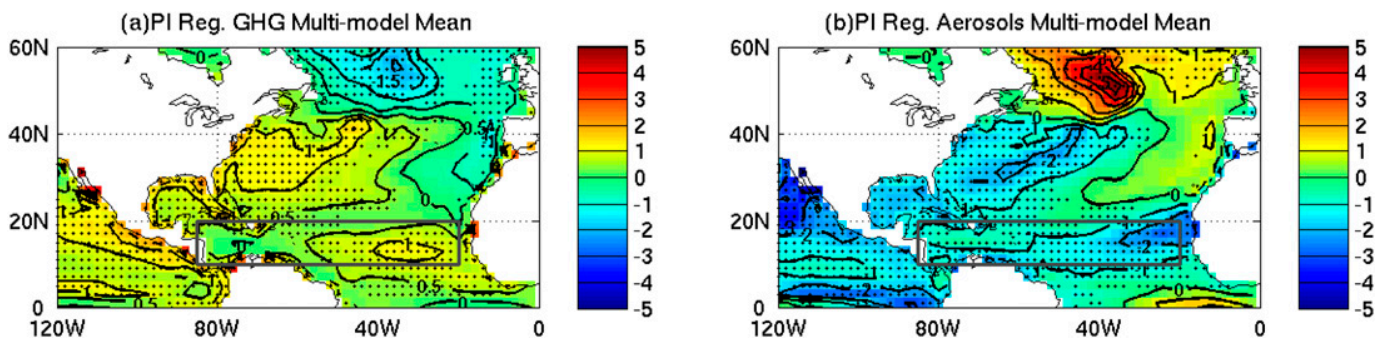

FIG. 9. Regression coefficients of PI onto forced (CC) component for (a) greenhouse-only and (b) aerosol-only simulations based on 9 CMIP5 models. The gray box indicates the MDR region. Regression coefficients are shown in meters per second per std dev of PC1 index in Fig. 8, and stippling represents 7 out of 9 models agree in the sign of the regression coefficients.

mean regression patterns are shown in Fig. 9 for the North Atlantic domain. The PI pattern associated with the historical GHG-only forcing (Fig. 9a) shares some resemblance to the historical total forcing regressions for the 26 models (Fig. 6b), but with less negative PI changes over the MDR region. The negative PI changes over the MDR region in the historical all-forcing case seem to be largely caused by the aerosol forcing (Fig. 9b). According to the models, aerosols also cause the PI decrease along the U.S. East Coast, in contrast to the PI changes due to GHG-only (Fig. 9a). While the SST patterns associated with aerosol-only forcing and that with GHG-only forcing are almost equal and opposite (with a spatial pattern correlation of -0.90 for the North Atlantic domain), the PI patterns are less similar (spatial pattern correlation of -0.53 ), indicating that there are substantial differences due to the responses of the atmospheric thermal structure to these two forcing agents. The spatial patterns of the PI change associated with aerosol forcing differ significantly from that associated with the AMV (Fig. 6a). The spatial pattern correlation between Fig. 6a for AMV PI and Fig. 9b for aerosol-only forced PI is only 0.21 over the North Atlantic domain. Thus, CMIP5 model simulations suggest that the aerosol forcing and the AMV, while sharing some similarities in their SST spatial signatures over the North Atlantic, are distinctly different from each other in terms of PI changes during the historical period.

The box-and-whiskers diagrams for the forced SST and PI changes associated with aerosol-only and GHGonly forcing are shown in Fig. 10. While the mean SST change associated with GHG-only $\left(0.33^{\circ} \mathrm{C}\right)$ is about (a) RMS of MDR SST (CMIP5)

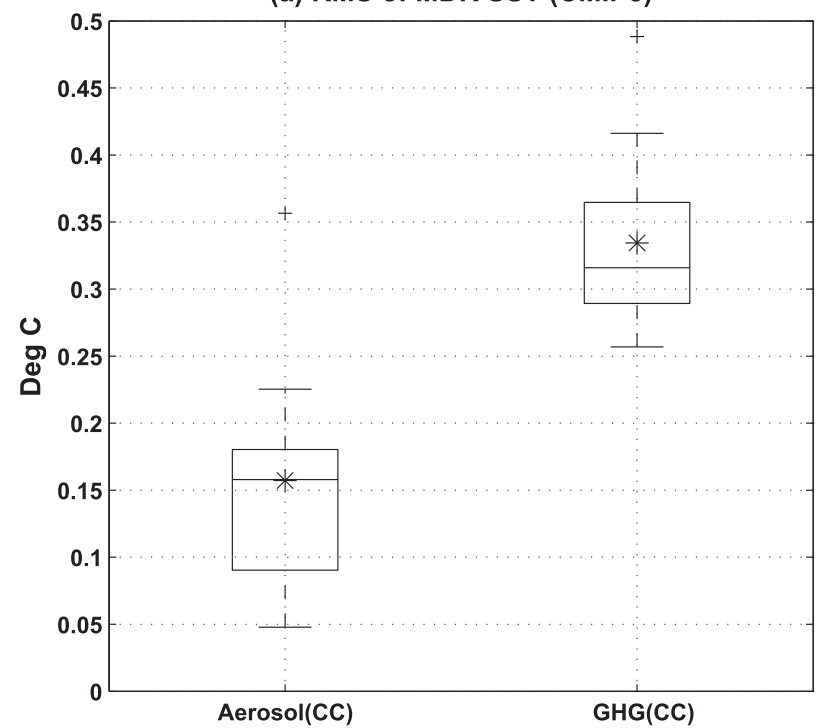

(b) RMS of MDR PI (CMIP5)

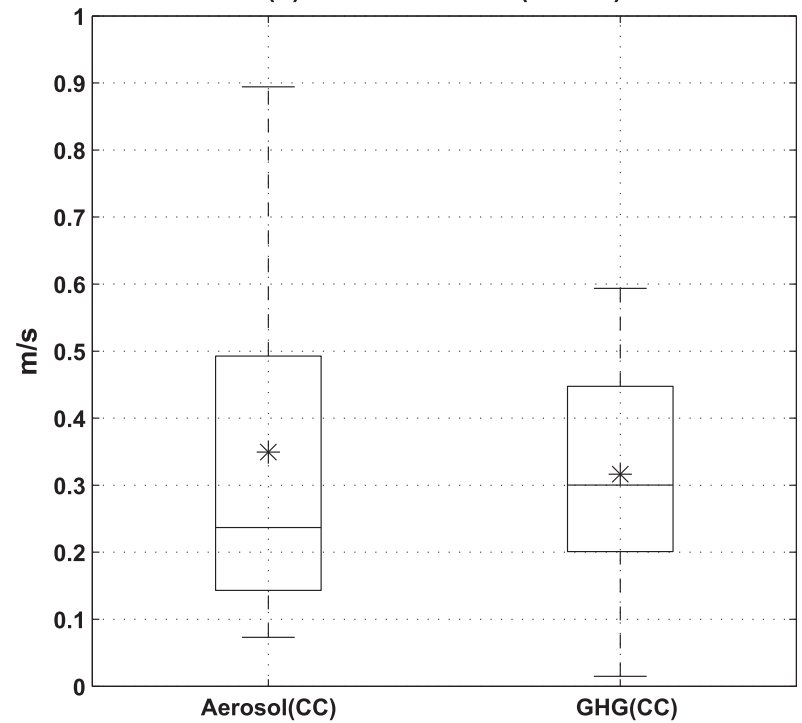

FIG. 10. Box-and-whiskers plot for (a) MDR SST $\left({ }^{\circ} \mathrm{C}\right)$ and (b) PI $\left(\mathrm{m} \mathrm{s}^{-1}\right)$ associated with the forced component for one member each from the 9 aerosol-only and GHG-only CMIP5 models. Box edges depict the middle $50 \%(25 \%-75 \%)$ of the data points, the lines inside the boxes depict the median, and asterisks depict the mean values; whiskers include $\pm 2.7 \mathrm{std} \operatorname{dev}(\sim 0.35 \%-99.65 \%)$ of the data points, and pluses indicate the outliers. 
TABLE 3. The median (boldface), $25 \%$, and $75 \%$ values of the ratio between the MDR PI and SST for the forced component of aerosol-only and GHG-only CMIP5 historical simulations (unit: $\mathrm{m} \mathrm{s}^{-1}$ per degree of SST).

\begin{tabular}{lccc}
\hline \hline & & Aerosol & GHG \\
\hline CC & $25 \%$ & 1.1852 & 0.5723 \\
& $\mathbf{5 0} \%$ & $\mathbf{2 . 1 5 0 1}$ & $\mathbf{0 . 6 4 6 8}$ \\
& $75 \%$ & 2.4852 & 0.9580 \\
\hline
\end{tabular}

twice as large as that associated with the aerosol-only $\left(0.16^{\circ} \mathrm{C}\right)$ forcing, the mean PI changes are similar for aerosol-only $\left(0.35 \mathrm{~m} \mathrm{~s}^{-1}\right)$ and for GHG-only $\left(0.31 \mathrm{~m} \mathrm{~s}^{-1}\right)$. CMIP5 model results suggest that the aerosol-forced SST in the MDR region is more effective in causing changes in PI than that for GHG-only forcing. Table 3 lists the SST to PI ratio and its uncertainty ranges based on the 9 models, and the median ratio for aerosol-only is about 3 times the ratio for GHG-only forcing. The results here are consistent with Emanuel and Sobel (2013), who found that the rate of PI increase with SST is much smaller when
SST warming is caused by increasing $\mathrm{CO}_{2}$ concentration, compared to that when SST warming is due to increasing the solar constant. The main reason for the difference between aerosol and GHG forcing is that the net surface radiative flux, which is essential for hurricane PI [see Eq. (4) in Emanuel and Sobel (2013)], approaches zero for $\mathrm{CO}_{2}$ forcing at equilibrium but continues to decrease in the case of aerosol forcing through reduction in solar radiation. Thus, despite the similarities of SST patterns forced by aerosols and GHG due to large-scale air-sea interactions (Xie et al. 2013), the regional impacts of the two forcing agents can be very different and nuanced. Note that the scatter in the PI due to aerosol in Fig. 10b is much larger than that for the GHGs and for the SST in general, which suggests that the uncertainty in aerosol forcing in CMIP5 models may have a larger impact on the PI uncertainty than that for SST.

To attribute the historical PI changes to the various mechanisms, we show in Fig. 11 the low-pass filtered MDR SST and PI time series for the historical period, from 1860 to 2005, as simulated by CMIP5 models. Also

(a) MDR SST Index for ASO Season

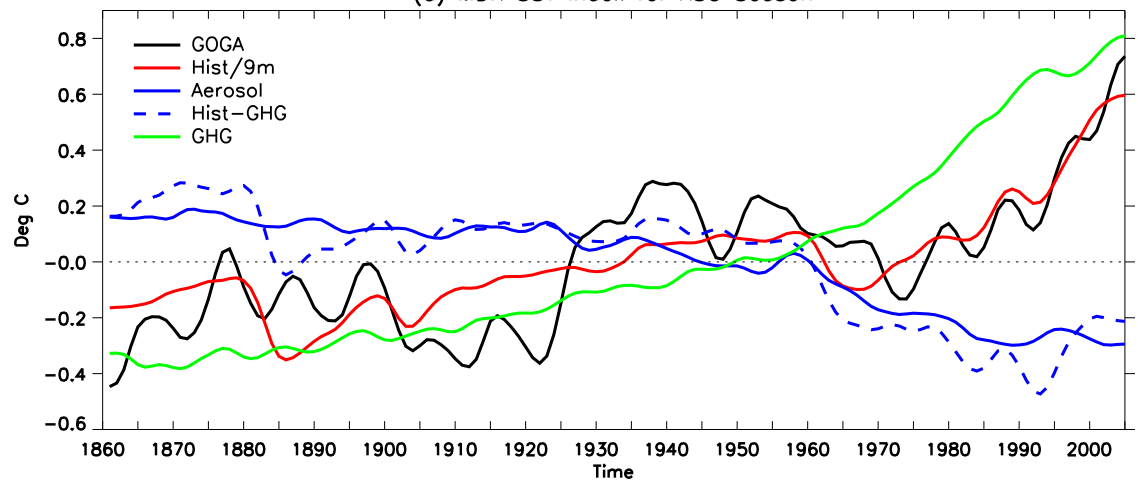

(b) MDR PI Index for ASO Season

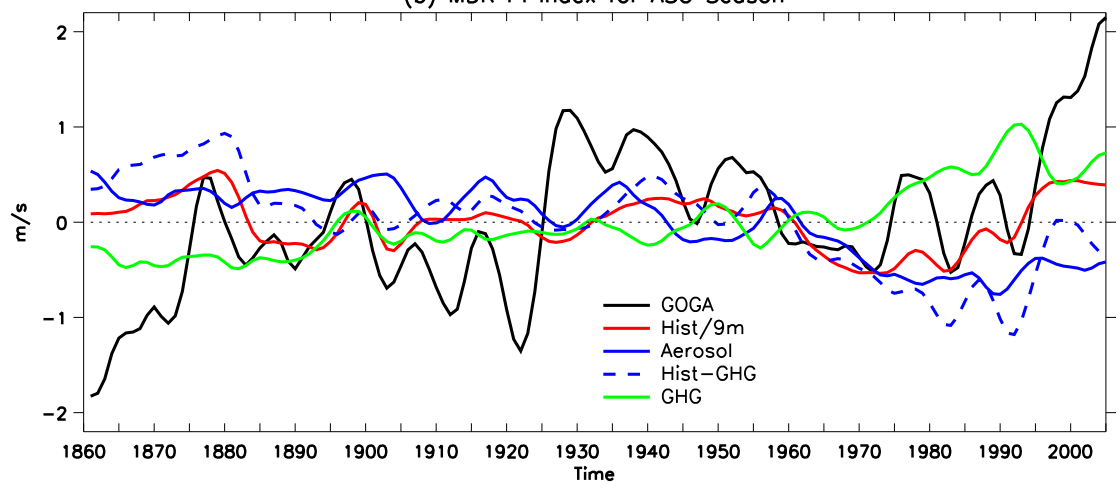

FIG. 11. (a) MDR SST and (b) PI averaged for the ASO season for observations (solid black), historical simulations (solid red), aerosol-only (solid blue), GHG-only (solid green), and historical minus GHG-only (dashed blue) for the years 1861-2005. Time series have been smoothed by the Butterworth filter with a cutoff frequency of $10 \mathrm{yr}$. The PI for the observational estimates are taken from an AGCM forced with prescribed observed SST, as in Camargo et al. 2013 . 
shown by the black solid line is the observed MDR SST and PI estimated from an atmospheric model forced with prescribed global observed SST [Global Ocean Global Atmosphere (GOGA)], as shown in Camargo et al. (2013). Note, however, that the PI estimated by prescribing global SST would be overestimated, according to Emanuel and Sobel (2013), because of the lack of a surface energy balance requirement in the AMIP type of model simulations. Thus, the PI estimated based on GOGA simulations in Fig. 11 may be overestimated and should be interpreted with care.

Throughout the historical period, anthropogenic aerosol forcing (blue solid line) contributes to a general cooling, while the GHG (green solid) causes a warming to the MDR SST. The SST associated with historical all forcing for the same 9 models (red solid line) is dominated by the greenhouse forcing and shows a general upward trend with some multidecadal fluctuations. However, these fluctuations are much smaller than the observed SST multidecadal changes (black line), consistent with Ting et al. (2009). When subtracting the GHG-only from the historical total (dashed blue line), the dashed blue line in Fig. 11a follows closely that for the aerosol-only forcing, indicating that in these model simulations the two forcing agents are approximately linearly additive. The significant deviations between the blue solid and dashed lines tend to correspond well with the known twentieth-century major volcanic eruptions (Driscoll et al. 2012). For the PI (Fig. 11b), there are larger-amplitude fluctuations associated with the GOGA simulations than in the corresponding SST. The PI values are possibly amplified because of the fixed SST experimental design (Emanuel and Sobel 2013), but in general they follow the same multidecadal fluctuations, with substantial increases for the last 35 years, starting from the beginning of the 1970s, consistent with the results of Emanuel (2005) and Villarini and Vecchi (2013) based on the power dissipation index. The observed accelerated increase in MDR SSTs since the 1970s (Fig. 11a) is well matched by the historical all-forcing multimodel mean and is dominated by the greenhouse gas forcing. However, the GOGA-simulated PI increases are much larger than the historical all-forcing simulations for the recent period, indicating a possible contribution from the natural variability (AMV). In particular, the sharp PI increase since 1995 in Fig. 11b, as simulated by the GOGA experiments, cannot be explained by any of the external radiative forcing and is consistent with the abrupt onset of the positive phase of the AMV around that time. Although the SST amplitude associated with aerosol-only forcing is smaller than that for GHG-only forcing, the magnitude of the simulated PI increases associated with aerosol-only forcing is comparable to that due to GHG, confirming the results in Table 3 that greenhouse gas forcing is less effective in causing PI changes. While the simulated SST increases in the last 30 years can be largely explained by the combination of the aerosols and GHG forcing (Fig. 11a), the different effectiveness of the PI changes as a function of SST for aerosol, GHG, and AMV (Tables 1 and 2) may render a different pictures for the PI changes in the last 30 years. Given the effectiveness of the aerosol forcing of the Atlantic hurricane PI changes, uncertainties in models' representations of aerosols (e.g., Evan et al. 2014) could contribute largely to the uncertainties of simulated historical and future PI changes due to external radiative forcing.

\section{Summary and conclusions}

We examined the historical and future hurricane intensity changes based on hurricane potential intensity, a quantity that depends on SST and large-scale atmospheric environmental variables, such as the convective available potential energy and the outflow temperature at the top of the tropopause. The pattern and time evolution of the PI in the 26 CMIP5 models' historical, RCP4.5, and RCP8.5 simulations with multiple ensemble members for each model (resulting in a total of 93 members for the historical, 56 for RCP4.5, and 60 for RCP8.5) is examined in terms of the externally forced and the internally generated components. On decadal and longer time scales, Atlantic multidecadal variability dominates the internal variability in the North Atlantic. During the historical past (1861-2005), the multidecadal variability in hurricane PI is larger than the corresponding forced component. However, by the end of the twenty-first century, the forced PI increases may be comparable to or larger than the amplitude associated with the AMV as simulated by the CMIP5 models using the RCP4.5 and RCP8.5 scenarios.

The positive AMV-related PI increases have large amplitudes mainly over the eastern basin of the North Atlantic extending to the tropical MDR region and very little contribution in the U.S. East Coast and the Gulf of Mexico regions. In contrast, model-projected PI increases due to climate change maximize along the U.S. East Coast and the Gulf of Mexico, potentially leading to stronger impacts on landfalling hurricane intensities and the coastal communities. When examining the MDR SST and PI amplitudes due to AMV and those due to radiative forcing, the results indicate that the AMV SST anomalies are much more effective in causing PI changes than those associated with climate change. The ratio of PI change per unit SST anomaly is about 3-4 times larger for AMV than for CC. This is consistent 
with previous studies emphasizing the role of relative SST change in causing PI changes rather than local SST (Vecchi and Soden 2007; Vecchi et al. 2008, Swanson 2007,2008 ) and the difference in PI dependence on SST, whether SST is radiatively forced or due to surface wind changes (Emanuel and Sobel 2013). Because of the local nature of the AMV SST pattern and because the tropical part of the AMV SST is possibly wind driven, it is not surprising that the AMV SST is much more effective than the CC-related SST, which is more global in nature and constrained by surface net radiation into the ocean.

We further examined the role of aerosol- and greenhouse gas-only forcing during the historical period and attribute the recent increases in potential intensity to greenhouse gases, aerosols, and natural multidecadal variability. The SST patterns associated with aerosolonly forcing and that with GHG-only forcing are almost equal and opposite (with a spatial pattern correlation of -0.90 for the North Atlantic domain). However, the PI patterns are less spatially opposite to each other, with a spatial pattern correlation of -0.53 , indicating that there are substantial local differences due to the responses of the atmospheric thermal structure to aerosols and greenhouse gases. One possible reason is that the PI changes depend on the net surface radiative flux into the ocean (Emanuel and Sobel 2013), which is relatively small for GHG forcing, while the reduction in solar radiation due to aerosol forcing is much stronger, rendering more effective PI changes due to aerosol forcing. For this reason, the amplitude of the PI change per unit MDR SST change shows that aerosol-forced SST is about 3 times more effective in causing the PI changes than GHG forcing. The effectiveness of aerosol forcing could potentially increase the uncertainty of the historical simulation and future model projections of Atlantic hurricane PI change in CMIP5 models, particularly those associated with African dust aerosols (Evan et al. 2014).

When further attributing the historical period PI changes using the CMIP5 models' historical all-forcing, aerosol-only, and GHG-only simulations, the PI changes during the historical period appear to be dominated by the natural multidecadal variability. The aerosol-forced PI decreases dominated the GHG-forced increases in PI in the MDR region, and the large recent increases in PI in the past decades are not completely explained by the radiative forcing, suggesting the possible role of the natural variability. We caution, however, that the relative importance of the radiatively forced and internally generated PI changes in the past few decades depends strongly on how well the models represent the historical aerosol forcing, which is known to contain large uncertainties. In the future, however, the forced increases in PI due to anthropogenic forcing are projected to become more dominant by the middle of the current century, and even a negative phase of the AMV would not be able to reduce the average potential intensity of the MDR region, or the tropical North Atlantic region, below the twentieth-century PI values.

Acknowledgments. The authors acknowledge support from the National Oceanic and Atmospheric Administration Grants NA10OAR4310124 and NA10OAR4310137, National Aeronautic and Space Agency Grant NASA \#14179R, and Office of Naval Research MURI Grant N00014-12-1-0911. We thank Haibo Liu for downloading and preprocessing the CMIP5 data used in this study. We thank Prof. Emanuel's insightful and detailed comments that substantially improved the manuscript. We also acknowledge two anonymous reviewers for their helpful comments.

\section{REFERENCES}

Allen, M. R., and L. A. Smith, 1997: Optimal filtering in singular spectrum analysis. Phys. Lett., 234, 419-428, doi:10.1016/ S0375-9601(97)00559-8.

Bellouin, N., J. Rae, A. Jones, C. Johnson, J. Haywood, and O. Boucher, 2011: Aerosol forcing in the Climate Model Intercomparison Project (CMIP5) simulations by HadGEM2ES and the role of ammonium nitrate. J. Geophys. Res., 116, D20206, doi:10.1029/2011JD016074.

Bender, M. A., T. R. Knutson, R. E. Tuleya, J. J. Sirutis, G. A. Vecchi, S. T. Garner, and I. M. Held, 2010: Modeled impact of anthropogenic warming on the frequency of intense Atlantic hurricanes. Science, 327, 454-458, doi:10.1126/ science. 1180568 .

Bengtsson, L., M. Botzet, and M. Esch, 1996: Will greenhouse gasinduced warming over the next 50 years lead to higher frequency and greater intensity of hurricanes? Tellus, 48A, 5773, doi:10.1034/j.1600-0870.1996.00004.x.

— , K. I. Hodges, M. Esch, N. Keenlyside, L. Kornblueh, J.-J. Luo, and T. Yamagata, 2007: How may tropical cyclones change in a warmer climate? Tellus, 59A, 539-561, doi:10.1111/ j.1600-0870.2007.00251.x.

Bister, M., and K. A. Emanuel, 1998: Dissipative heating and hurricane intensity. Meteor. Atmos. Phys., 65, 233-240, doi:10.1007/ BF01030791.

$\ldots$, and —_, 2002a: Low frequency variability of tropical cyclone potential intensity: 1. Interannual to interdecadal variability. J. Geophys. Res., 107, 4801, doi:10.1029/ 2001JD000776.

$\longrightarrow$, and — 2002b: Low frequency variability of tropical cyclone potential intensity: 2. Climatology for 1982-1995. J. Geophys. Res., 107, 4621, doi:10.1029/2001JD000780.

Blake, E. S., T. B. Kimberlain, R. J. Berg, J. P. Cangialosi, and J. L. Beven II, 2013: Tropical cyclone report: Hurricane Sandy. National Hurricane Center Rep. AL182012, 157 pp. [Available online at http://www.nhc.noaa.gov/data/tcr/AL182012_Sandy.pdf].

Booth, B. B. B., N. J. Dunstone, P. R. Halloran, T. Andrews, and N. Bellouin, 2012: Aerosols implicated as a prime driver of twentieth-century North Atlantic climate variability. Nature, 484, 228-232, doi:10.1038/nature10946. 
Butterworth, S., 1930: On the theory of filter amplifiers. Exp. Wireless, 7, 536-541.

Camargo, S. J., 2013: Global and regional aspects of tropical cyclone activity in the CMIP5 models. J. Climate, 26, 9880-9902, doi:10.1175/JCLI-D-12-00549.1.

- M. Ting, and Y. Kushnir, 2013: Influence of local and remote SST on North Atlantic tropical cyclone potential intensity. Climate Dyn., 40, 1515-1529, doi:10.1007/s00382-012-1536-4.

_-, M. Tippett, A. Sobel, G. Vecchi, and M. Zhao, 2014: Testing the performance of tropical cyclone genesis indices in future climates using the HiRAM model. J. Climate, 27, 9171-9196, doi:10.1175/JCLI-D-13-00505.1.

Chang, C.-Y., J. C. H. Chiang, M. F. Wehner, A. R. Friedman, and R. Ruedy, 2011: Sulfate aerosol control of tropical Atlantic climate over the twentieth century. J. Climate, 24, 2540-2555, doi:10.1175/2010JCLI4065.1.

DelSole, T., M. K. Tippett, and J. Shukla, 2011: A significant component of unforced multidecadal variability in the recent acceleration of global warming. J. Climate, 24, 909-926, doi:10.1175/2010JCLI3659.1.

Driscoll, S., A. Bozzo, L. J. Gray, A. Robock, and G. Stenchikov, 2012: Coupled Model Intercomparison Project 5 (CMIP5) simulations of climate following volcanic eruptions. J. Geophys. Res., 117, D17105, doi:10.1029/2012JD017607.

Elsner, J. B., J. P. Kossin, and T. H. Jagger, 2008: The increasing intensity of the strongest tropical cyclones. Nature, 455, 92-95, doi:10.1038/nature07234.

Emanuel, K. A., 1987: The dependence of hurricane intensity on climate. Nature, 326, 483-485, doi:10.1038/326483a0.

, 1988: The maximum intensity of hurricanes. J. Atmos. Sci., 45, 1143 1155, doi:10.1175/1520-0469(1988)045<1143:TMIOH>2.0.CO;2.

- 1995: Sensitivity of tropical cyclones to surface exchange coefficients and a revised steady-state model incorporating eye dynamics. J. Atmos. Sci., 52, 3969-3976, doi:10.1175/ 1520-0469(1995)052<3969:SOTCTS $>2.0$. CO 2 .

_ 2005: Increasing destructiveness of tropical cyclones over the past 30 years. Nature, 436, 686-688, doi:10.1038/nature03906.

_ 2011: Global warming effects on U.S. hurricane damage. Wea. Climate Soc., 3, 261-268, doi:10.1175/WCAS-D-11-00007.1.

_ 2013: Downscaling CMIP5 climate models shows increased tropical cyclone activity over the 21st century. Proc. Natl. Acad. Sci. USA, 110, 12 219-12 224, doi:10.1073/pnas.1301293110.

__ and A. Sobel, 2013: Response of tropical sea surface temperature, precipitation, and tropical cyclone-related variables to changes in global and local forcing. J. Adv. Model. Earth Sys., 5, 447-458, doi:10.1002/jame.20032.

— , R. Sundararajan, and J. Williams, 2008: Hurricanes and global warming: Results from downscaling IPCC AR4 simulations. Bull. Amer. Meteor. Soc., 89, 347-367, doi:10.1175/BAMS-89-3-347.

Evan, A. T., and Coauthors, 2008: Ocean temperature forcing by aerosols across the Atlantic tropical cyclone development region. Geochem. Geophys. Geosyst., 9, Q05V04, doi:10.1029/ 2007 GC001774.

- D. J. Vimont, A. K. Heidinger, J. P. Kossin, and R. Bennartz, 2009: The role of aerosols in the evolution of tropical North Atlantic Ocean temperature anomalies. Science, 324, 778-781, doi:10.1126/science.1167404.

— C. Flamant, S. Fiedler, and O. Doherty, 2014: An analysis of aeolian dust in climate models. Geophys. Res. Lett., 41, 59966001, doi:10.1002/2014GL060545.

Graumann, A., T. Houston, J. Lawrimore, D. Levinson, N. Lott, S. McCown, S. Stephens, and D. Wuertz, 2005: Hurricane Katrina: A climatological perspective. NOAA's National Climatic
Data Center Tech. Rep. 2005-01, 27 pp. [Available online at https://www.ncdc.noaa.gov/oa/reports/tech-report-200501z.pdf.]

Henderson-Sellers, A., and Coauthors, 1998: Tropical cyclones and global climate change: A post-IPCC assessment. Bull. Amer. Meteor. Soc., 79, 19-38, doi:10.1175/1520-0477(1998)079<0019: TCAGCC $>2.0 . \mathrm{CO} ; 2$.

Hill, K. A., and G. M. Lackmann, 2011: The impact of climate change on TC intensity and structure: A downscaling approach. J. Climate, 24, 4644-4661, doi:10.1175/2011JCLI3761.1.

Holland, G. J., 1997: The maximum potential intensity of tropical cyclones. J. Atmos. Sci., 54, 2519-2541, doi:10.1175/ 1520-0469(1997)054<2519:TMPIOT>2.0.CO;2.

— , and P. J. Webster, 2007: Heightened tropical cyclone activity in the North Atlantic: Natural variability or climate trend? Philos. Trans. Roy. Soc. London, A365, 2695-2716, doi:10.1098/ rsta.2007.2083.

Kalnay, E., and Coauthors, 1996: The NCEP/NCAR 40-Year Reanalysis Project. Bull. Amer. Meteor. Soc., 77, 437-471, doi:10.1175/1520-0477(1996)077<0437:TNYRP>2.0.CO;2.

Kistler, R., and Coauthors, 2001: The NCEP-NCAR 50-Year Reanalysis: Monthly means CD-ROM and documentation. Bull. Amer. Meteor. Soc., 82, 247-267, doi:10.1175/ 1520-0477(2001)082<0247:TNNYRM >2.3.CO;2.

Knutson, T. R., and R. E. Tuleya, 2004: Impact of $\mathrm{CO}_{2}$-induced warming on simulated hurricane intensity and precipitation: Sensitivity to the choice of climate model and convective parameterization. J. Climate, 17, 3477-3495, doi:10.1175/ 1520-0442(2004)017<3477:IOCWOS>2.0.CO;2.

,-- , and Y. Kurihara, 1998: Simulated increase of hurricane intensities in a $\mathrm{CO}_{2}$-warmed climate. Science, 279, 1018-1021, doi:10.1126/science.279.5353.1018.

— , and Coauthors, 2010: Tropical cyclones and climate change. Nat. Geosci., 3, 157-163, doi:10.1038/ngeo779.

— twenty-first-century Atlantic hurricane activity: CMIP3 and CMIP5 model-based scenarios. J. Climate, 26, 6591-6617, doi:10.1175/JCLI-D-12-00539.1.

Kossin, J. P., K. R. Knapp, D. J. Vimont, R. J. Murnane, and B. A. Harper, 2007: A globally consistent reanalysis of hurricane variability and trends. Geophys. Res. Lett., 34, L04815, doi:10.1029/ 2006 GL028836.

— T. T. Olander, and K. R. Knapp, 2013: Trend analysis with a new global record of tropical cyclone intensity. J. Climate, 26, 9960-9976, doi:10.1175/JCLI-D-13-00262.1.

Li, W., L. Li, M. Ting, and Y. Liu, 2012: Intensification of Northern Hemisphere subtropical highs in a warming climate. Nat. Geosci., 5, 830-834, doi:10.1038/ngeo1590.

Lin, N., K. Emanuel, M. Oppenheimer, and E. Vanmarcke, 2012: Physically based assessment of hurricane surge threat under climate change. Nat. Climate Change, 2, 462-467, doi:10.1038/ nclimate1389.

Maloney, E. D., and Coauthors, 2014: North American climate in CMIP5 experiments: Part III: Assessment of twenty-firstcentury projections. J. Climate, 27, 2230-2270, doi:10.1175/ JCLI-D-13-00273.1.

Mann, M. E., and K. A. Emanuel, 2006: Atlantic hurricane trends linked to climate change. Eos, Trans. Amer. Geophys. Union, 87, 233-241, doi:10.1029/2006EO240001.

Meehl, G. A., W. M. Washington, D. J. Erickson III, B. P. Briegleb, and P. J. Jaumann, 1996: Climate change from increased $\mathrm{CO}_{2}$ and direct and indirect effects of sulfate aerosols. Geophys. Res. Lett., 23, 3755-3758, doi:10.1029/ 96GL03478. 
Mendelsohn, R., K. Emanuel, S. Chonabayashi, and L. Bakkensen, 2012: The impact of climate change on tropical cyclone damage. Nat. Climate Change, 2, 205-209, doi:10.1038/ nclimate1357.

Murakami, H., and Coauthors, 2012: Future changes in tropical cyclone activity projected by the new high-resolution MRI-AGCM. J. Climate, 25, 3237-3260, doi:10.1175/JCLI-D-11-00415.1.

Reynolds, R. W., N. A. Rayner, T. M. Smith, D. C. Stokes, and W. Wang, 2002: An improved in situ and satellite SST analysis for climate. J. Climate, 15, 1609-1625, doi:10.1175/ 1520-0442(2002)015<1609:AIISAS > 2.0.CO;2.

Russell, G. L., and D. Rind, 1999: Response to $\mathrm{CO}_{2}$ transient increase in the GISS coupled model: Regional coolings in a warming climate. J. Climate, 12, 531-539, doi:10.1175/ 1520-0442(1999)012<0531:RTCTII >2.0.CO;2.

Swanson, K. L., 2007: Impact of scaling behavior on tropical cyclone intensities. Geophys. Res. Lett., 34, L18815, doi:10.1029/ 2007GL030851.

- 2008: Nonlocality of tropical cyclone intensities. Geochem. Geophys. Geosyst., 9, Q04V01, doi:10.1029/2007GC001844.

Taylor, K. E., R. J. Stouffer, and G. A. Meehl, 2012: An overview of CMIP5 and the experiment design. Bull. Amer. Meteor. Soc., 93, 485-498, doi:10.1175/BAMS-D-11-00094.1.

Ting, M., Y. Kushnir, R. Seager, and C. Li, 2009: Forced and natural twentieth-century SST trends in the North Atlantic. J. Climate, 22, 1469-1481, doi:10.1175/2008JCLI2561.1.

$\ldots,-, \ldots$, and — 2011: Robust features of Atlantic multidecadal variability and its climate impacts. Geophys. Res. Lett., 38, L17705, doi:10.1029/2011GL048712.
,-- , and C. Li, 2014: North Atlantic Multidecadal SST Oscillation: External forcing versus internal variability. J. Mar. Syst., 133, 27-38, doi:10.1016/j.jmarsys.2013.07.006.

Vecchi, G. A., and B. J. Soden, 2007: Effect of remote sea surface temperature change on tropical cyclone potential intensity. Nature, 450, 1066-1070, doi:10.1038/nature06423.

—, K. L. Swanson, and B. J. Soden, 2008: Whither hurricane activity? Science, 322, 687-689, doi:10.1126/science.1164396.

Villarini, G., and G. A. Vecchi, 2013: Projected increases in North Atlantic tropical cyclone intensity from CMIP5 models. J. Climate, 26, 3631-3643, doi:10.1175/JCLI-D-12-00441.1.

Wilcox, L. J., E. J. Highwood, and N. J. Dunstone, 2013: The influence of anthropogenic aerosol on multi-decadal variations of historical global climate. Environ. Res. Lett., 8, 024033 , doi:10.1088/1748-9326/8/2/024033.

Wood, R. A., A. B. Keen, J. F. B. Mitchell, and J. M. Gregory, 1999: Changing spatial structure of the thermohaline circulation in response to atmospheric $\mathrm{CO}_{2}$ forcing in a climate model. Nature, 399, 572-575, doi:10.1038/21170.

Xie, S.-P., B. Lu, and B. Xiang, 2013: Similar spatial patterns of climate responses to aerosol and greenhouse gas changes. Nat. Geosci., 6, 828-832, doi:10.1038/ngeo1931.

Zhang, R., and Coauthors, 2013: Have aerosols caused the observed Atlantic multidecadal variability? J. Atmos. Sci., 70, 1135-1144, doi:10.1175/JAS-D-12-0331.1.

Zhao, M., and I. M. Held, 2010: An analysis of the effect of global warming on the intensity of Atlantic hurricanes using a GCM with statistical refinement. J. Climate, 23, 6382-6393, doi:10.1175/2010JCLI3837.1. 